\title{
Boosting Hydrazine Oxidation Reaction on CoP/Co Mott-Schottky Electrocatalyst through Engineering Active Sites
}

Shi Chen ${ }^{1}$, Changlai Wang ${ }^{1,3}$, Shuai Liu ${ }^{1}$, Minxue Huang ${ }^{1}$, Jian Lu ${ }^{1}$, Pengping Xü, Huigang Tong ${ }^{1}$, Lin Hu², Qianwang Chen ${ }^{1,2 *}$

${ }^{1}$ Hefei National Laboratory for Physical Science at Microscale and Department of Materials Science and Engineering, University of Science and Technology of China, Hefei 230026, China

${ }^{2}$ The Anhui High Magnetic Field Laboratory, Hefei Institutes of Physical Science, Chinese Academy of Sciences, Hefei, Anhui 230031, P. R. China

${ }^{3}$ Department of Materials Science and Engineering, Center of Super-Diamond and Advanced Films (COSDAF), City University of Hong Kong, Tat Chee Avenue, Kowloon, Hong Kong, China

\section{AUTHOR INFORMATION}

\section{Corresponding Author}

* Qianwang Chen

*E-mail: cqw@ustc.edu.cn 


\section{Contents}

Number of pages: 24

Number of figures: 30

Number of tables: 10

1. Experimental section

2. Materials characterization

3. Electrocatalytic measurements details

4. Calculation details

5. Supplementary Figures and Tables

Figure S1, Figure S5-Figure S8. The characterization (TEM and FESEM) of Co NPs, CoP and CoP/Co-n samples

Figure S2. XRD patterns of the as-prepared $\mathrm{Co}_{3}\left[\mathrm{Co}(\mathrm{CN})_{6}\right]_{2}$

Figure S3, Figure S4. TGA/DTG curves of as-prepared $\mathrm{Co}_{3}\left[\mathrm{Co}(\mathrm{CN})_{6}\right]_{2}$, Co NPs, $\mathrm{CoP} / \mathrm{Co}-20$.

Figure S9. Typical XRD patterns of $\mathrm{CoP} / \mathrm{Co}-5$, CoP/Co-10, CoP/Co-20, and CoP/Co30 .

Figure S10. Weight gain curves for phosphating with different mass ratios of $\mathrm{NaH}_{2} \mathrm{PO}_{2} \cdot \mathrm{H}_{2} \mathrm{O}$ and Co NPs.

Figure S11-Figure S14. XPS characterization of Co NPs, CoP, and CoP/Co-n samples.

Figure S15. $\mathrm{N}_{2}$ adsorption/desorption isotherms of $\mathrm{CoP} / \mathrm{Co}-20$ sample.

Figure S16. $\mathrm{N}_{2}$ adsorption/desorption isotherms of Co NPs and CoP/Co-n samples.

Figure S17. Hydrazine oxidation LSV polarization curves of $\mathrm{CoP} / \mathrm{Co}-20$ in $1.0 \mathrm{M}$ $\mathrm{KOH}$ containing different hydrazine concentrations.

Figure S18. CV curves measured within the range of -0.127 to $-0.027 \mathrm{~V}$ vs. RHE with scan rate from 10 to $120 \mathrm{mV} \mathrm{s}^{-1}$ of Co NPs, CoP and CoP/Co-n samples

Figure S19. $\mathrm{C}_{\mathrm{dl}}$ values estimated through linear fitting of the scan rate of Co NPs, $\mathrm{CoP}$ and $\mathrm{CoP} / \mathrm{Co}-\mathrm{n}$ samples.

Figure S20. Electrochemical impedance spectroscopy (EIS) for Co NPs, CoP and $\mathrm{CoP} / \mathrm{Co}-\mathrm{n}$ samples before and after HzOR tests.

Figure S21. Electrochemical impedance spectroscopy (EIS) for Co NPs, CoP and $\mathrm{CoP} / \mathrm{Co}-\mathrm{n}$ samples in 1.0 M KOH without hydrazine. 
Figure S22-Figure S24. The FESEM, TEM images, XRD patterns, XPS characterization of $\mathrm{CoP} / \mathrm{Co}-20$ after stability test.

Figure S25-Figure S30. The corresponding calculation models and results of Co NPs and $\mathrm{CoP} / \mathrm{Co}-20$

Table S1. ICP-MS analysis of Co ions of CoP/Co-n samples

Table S2. Atomic concentrations at the surface of the Co NPs, CoP and CoP/Co-n samples determined by XPS

Table S3-Table S4. Peak assignments from deconvolution of high resolution Co $2 p$ and P $2 \mathrm{p}$ of Co NPs, CoP and CoP/Co-n samples.

Table S5. Statistical results of BET surface area and BJH adsorption average pore diameter of Co NPs and CoP/Co-n samples

Table S6. Comparison of the electrocatalytic activities of Co NPs and CoP/Co-n samples for $\mathrm{HzOR}$.

Table S7. Comparison of the electrocatalytic activities of $\mathrm{CoP} / \mathrm{Co}-20$ with other reported cobalt based and precious metal base materials for $\mathrm{HzOR}$

Table S8- Table S10. Comparison of the Tafel slope, ECSA, Rct of Co NPs and $\mathrm{CoP} / \mathrm{Co}-\mathrm{n}$ samples for $\mathrm{HzOR}$

6. Reference

\section{Experimental section}

Materials: All reagents are of analytical grade and used without purification. Cobaltous acetate tetrahydrate $\left(\mathrm{Co}\left(\mathrm{CH}_{3} \mathrm{COO}\right)_{2} \cdot 4 \mathrm{H}_{2} \mathrm{O}\right)$, Polyvinylpyrrolidone $\mathrm{K}-30\left(\left(\mathrm{C}_{6} \mathrm{H}_{9} \mathrm{NO}\right)_{6}\right.$, PVP), Sodium hypophosphite $\left(\mathrm{NaH}_{2} \mathrm{PO}_{2} \cdot \mathrm{H}_{2} \mathrm{O}\right)$, Ethanol absolute $\left(\mathrm{C}_{2} \mathrm{H}_{5} \mathrm{OH}\right)$ and Hydrazine hydrate $\left(\mathrm{N}_{2} \mathrm{H}_{4} \cdot \mathrm{H}_{2} \mathrm{O}\right)$ were purchased from Sinopharm Chemical Reagent limited corporation. Potassium hexacyanocobaltate (III) $\left(\mathrm{K}_{3}\left[\mathrm{Co}(\mathrm{CN})_{6}\right]_{2}\right)$ was purchased from J\&K Scientific Ltd.. Benzene-1,3,5-Benzenetricarboxylic acid $\left(\mathrm{C}_{9} \mathrm{H}_{6} \mathrm{O}_{6}, \mathrm{BTC}\right)$ were purchased from J\&K Scientific Ltd.. The deionized water used throughout all experiments was purified through a Millipore system.

$\mathrm{Co}_{3}\left[\mathrm{Co}(\mathrm{CN})_{6}\right]_{2}$ synthesis: The cubic $\mathrm{Co}_{3}\left[\mathrm{Co}(\mathrm{CN})_{6}\right]_{2}$ particles, used as MOF precursors, were synthesized according to previous research with some modifications. ${ }^{1}$ The typical synthetic experiments were as follows: Solution A: $37.4 \mathrm{mg} \mathrm{Co}\left(\mathrm{CH}_{3} \mathrm{COO}\right)_{2} \cdot 4 \mathrm{H}_{2} \mathrm{O}$ was dissolved in deionized water $(15 \mathrm{~mL})$. Solution B: $33.2 \mathrm{mg} \mathrm{K}_{3}\left[\mathrm{Co}(\mathrm{CN})_{6}\right]_{2}$ and $600 \mathrm{mg}$ PVP were dissolved in deionized water $(15 \mathrm{ml})$. Then, the solution A was added to the solution B slowly and regularly with a syringe under agitated stirring. The mixture was stirred for $30 \mathrm{~min}$ and aged at room temperature for $12 \mathrm{~h}$. The resulting pink sample was collected by centrifugation, washed three times with deionized water and one time 
with ethanol, and thus dried in a vacuum oven at room temperature for $12 \mathrm{~h}$.

Co NPs synthesis: The as-prepared $\mathrm{Co}_{3}\left[\mathrm{Co}(\mathrm{CN})_{6}\right]_{2}$ synthesis $(500 \mathrm{mg})$ was heated at $600{ }^{\circ} \mathrm{C}$ for $3 \mathrm{~h}$ in the nitrogen atmosphere and the heating rate is $5{ }^{\circ} \mathrm{C} / \mathrm{min}$.

CoP/Co- $n$ synthesis: Co NPs $(50 \mathrm{mg})$ synthesis was placed downstream of the tube furnace, and $\mathrm{NaH}_{2} \mathrm{PO}_{2} \cdot \mathrm{H}_{2} \mathrm{O}$ with different amount $(250 \mathrm{mg}, 500 \mathrm{mg}, 1000 \mathrm{mg}, 1500$ $\mathrm{mg}$ ) was placed upstream of the tube furnace, respectively, and then annealed at $300^{\circ} \mathrm{C}$ for $3 \mathrm{~h}$ under $\mathrm{N}_{2}$ with the heating rate of $2{ }^{\circ} \mathrm{C} / \mathrm{min}$. Caution! The nitrogen flow rate is controlled at one bubble every three seconds, and the exhaust $\mathrm{PH}_{3}$ should be collected with copper sulfate solution. According to the mass ratio of $\mathrm{NaH}_{2} \mathrm{PO}_{2} \cdot \mathrm{H}_{2} \mathrm{O}$ and Co NPs, the $\mathrm{CoP} / \mathrm{Co}-\mathrm{n}$ synthesis were named as $\mathrm{CoP} / \mathrm{Co}-5$ (the mass ratio of $\mathrm{NaH}_{2} \mathrm{PO}_{2} \cdot \mathrm{H}_{2} \mathrm{O}$ and Co NPs is 5:1), CoP/Co-10, $\mathrm{CoP} / \mathrm{Co}-20, \mathrm{CoP} / \mathrm{Co}-30$, respectively.

Co-BTC synthesis: The virgulate Co-BTC were synthesized according to previous research with some modifications. ${ }^{2}$ Solution A: $90 \mathrm{mg}$ 1,3,5-Benzenetricarboxylic acid was dissolved in an ethanol/water $(20 / 20 \mathrm{ml})$ system. Solution B: $50 \mathrm{mg}$ $\mathrm{Co}\left(\mathrm{CH}_{3} \mathrm{COO}\right)_{2} \cdot 4 \mathrm{H}_{2} \mathrm{O}$ and $300 \mathrm{mg}$ PVP were dissolved in an ethanol/water $(20 / 20 \mathrm{ml})$ system. Then, the solution A was added to the solution B slowly and regularly with a syringe under agitated stirring. The mixture was stirred for $30 \mathrm{~min}$ and aged at room temperature for $12 \mathrm{~h}$. The resulting sample was collected by centrifugation, washed three times with deionized water and one time with ethanol, and thus dried in a vacuum oven at room temperature for $12 \mathrm{~h}$.

CoP synthesis: The as-prepared Co-BTC synthesis was heated at $600{ }^{\circ} \mathrm{C}$ for $3 \mathrm{~h}$ in the nitrogen atmosphere and the heating rate is $5{ }^{\circ} \mathrm{C} / \mathrm{min}$, afterwards, the carbonized product $\left(50 \mathrm{mg}\right.$ ) was placed downstream of the tube furnace, and $\mathrm{NaH}_{2} \mathrm{PO}_{2} \cdot \mathrm{H}_{2} \mathrm{O}(1500$ $\mathrm{mg}$ ) was placed upstream of the tube furnace, respectively, and then annealed at $300^{\circ} \mathrm{C}$ for $3 \mathrm{~h}$ under $\mathrm{N}_{2}$ with the heating rate of $2{ }^{\circ} \mathrm{C} / \mathrm{min}$. Caution! The nitrogen flow rate is controlled at one bubble every three seconds, and the exhaust $\mathrm{PH}_{3}$ should be collected with copper sulfate solution.

\section{Materials characterization}

The powder X-ray diffraction (XRD) patterns of the samples were collected from a Japan Rigaku D/MAX- $\gamma \mathrm{A}$ X-ray diffractometer equipped with $\mathrm{Cu} \mathrm{K} \alpha$ radiation $(\lambda=1.54178 \AA$ ). Field emission scanning electron microscopy (FESEM) images were recorded on a JEOLJSM-6700 M scanning electron microscope. Transmission electron microscopy (TEM) images were recorded with a Hitachi H-7650 transmission electron microscope using an accelerating voltage of $200 \mathrm{kV}$, and a high resolution transmission electron microscope (HRTEM) (JEOL-2011) was operated at an acceleration voltage of $200 \mathrm{kV}$. Raman spectra were recorded with a LabRAM HR Raman spectrometer ranging from 200 to $3000 \mathrm{~cm}^{-1}$. TG-DTA was carried out using a SDT Q600 (V20.9 Build 20) equipment (TA Company, USA). X-ray photoelectron spectroscopy (XPS) was conducted on an ESCALAB 250 X-ray photoelectron spectrometer instrument. The specific surface area was evaluated at $77 \mathrm{~K}$ using the Brunauer-Emmett-Teller (BET) method (Micromeritic TriStar II 3020 V1.03 instrument), while the pore volume 
and pore size were calculated according to the Barrett-Joyner-Halenda (BJH) formula applied to the adsorption branch. Inductively coupled plasma-atomic emission spectrometer (ICP-AES) were conducted to determine the Co concentrations of the samples with an Optima 7300 DV instrument. XANES spectra at the Co L-edge were obtained at the beamline BL08U1A(National Synchrotron Radiation Laboratory (NSRL)).

\section{Electrocatalytic measurements details}

All electrochemical experiments were performed in a standard three-electrode cell at room temperature (Caution! Only the overall hydrazine splitting $(\mathrm{OHzS})$ and overall water splitting (OWS) experiments were performed in a two-electrode cell at room temperature as well). The cell consists of a L-shaped glassy carbon working electrode (GC electrode, $5 \mathrm{~mm}$ in diameter, loading $\sim 0.275 \mathrm{mg} \mathrm{cm}^{-2}$ ), an $\mathrm{Ag} / \mathrm{AgCl}$ reference electrode, and a graphite rod counter electrode. All potentials in this study are given relative to the reversible hydrogen electrode (RHE) after transformation $\left(\mathrm{E}_{\mathrm{RHE}}=\right.$ $\left.\mathrm{E}_{\mathrm{Ag} / \mathrm{AgCl}}+0.197+0.0591 \mathrm{pH}\right)$. Overpotential $\eta(\mathrm{V})=\mathrm{E}(\mathrm{RHE})-1.23 \mathrm{~V}$. The working electrodes were prepared by applying catalyst ink onto glassy carbon (GC). The GC eleatrodes should be carefully polished with $\mathrm{Al}_{2} \mathrm{O}_{3}$ powders with a size of $0.05 \mu \mathrm{m}$ and rinsed with deionized water before adding catalysts onto the GC. Typically, $4 \mathrm{mg}$ of catalyst was dispersed in a solution containing $1 \mathrm{~mL}$ of the ethanol solvent and $30 \mu \mathrm{L}$ Nafion solution (Sigma Aldrich, $5 \mathrm{wt} \%$ ) and ultrasonicated for at least 30 minutes to form a uniform catalyst ink. A total of $14 \mu \mathrm{L}$ of well-dispersed catalyst ink was applied onto the pre-polished GC disk. The prepared electrodes were dried at room temperature before electrochemical tests. The polarization curves were collected of working electrodes in $1 \mathrm{M} \mathrm{KOH}$ with $0.5 \mathrm{M} \mathrm{N}_{2} \mathrm{H}_{4}$ a with a scan rate of $5 \mathrm{mV} / \mathrm{s}$, after the signals were stabilized via. several scans. Cyclic voltammetry $(\mathrm{CV})$ was conducted in acidic media in the potential region from -1.221 to $-0.281 \mathrm{~V}$ versus $\mathrm{Ag} / \mathrm{AgCl}$ electrode at a sweep rate of $100 \mathrm{mV} / \mathrm{s}$ for 5000 to investigate the long-term cycling stability. All the electrolyses were conducted at room temperature. Besides, chronopotentiometric electrolysis of the working electrode was held at a current density of $10 \mathrm{~mA} \mathrm{~cm}{ }^{-2}$ for 10 hours. All the electrolysis was conducted at room temperature, and IR correction was not applied in all measurements.Nyquist plots of Electrochemical impedance spectroscopy (EIS) measurements were collected in frequency range of $0.01-10^{6} \mathrm{~Hz}$ at $-1.09 \mathrm{~V}$ vs. $\mathrm{Ag} / \mathrm{AgCl}$ electrode (open circuit potential). The electrical double layer capacitor $\left(\mathrm{C}_{\mathrm{dl}}\right)$ were measured from double-layer charging curves using cyclic voltammograms in a small potential range of -1.15-1.05 V vs. $\mathrm{Ag} / \mathrm{AgCl}$ electrode with scan rate from 10 to $120 \mathrm{mV} / \mathrm{s}$. The plot of the corresponding current density $(\Delta \mathrm{j} / 2$ at $-1.10 \mathrm{~V}$ vs. $\mathrm{Ag} / \mathrm{AgCl}$ electrode) against scan rate has a linear relationship and its slope is the $\mathrm{C}_{\mathrm{dl}}$. The ECSA is calculated from the double layer capacitance according to: ${ }^{3}$

$$
\mathrm{ECSA}=\mathrm{C}_{\mathrm{dl}} \cdot \mathrm{S} / \mathrm{Cs}
$$

Where Cs is the specific capacitance of the sample. We use general specific capacitances of $\mathrm{Cs}=0.06 \mathrm{mF} \mathrm{cm}{ }^{-2}$ based on typical reported values, ${ }^{4} \mathrm{~S}$ is the geometric area of the electrode. The roughness factor (RF) is calculated by dividing ECSA by $0.196 \mathrm{~cm}^{2}$, the geometric area of the electrode. 


\section{Calculation details}

All theoretical calculations were performed based on density functional theory (DFT), as implemented in the Vienna ab-initio simulation package (VASP) $)^{1,2}$. The exchangecorrelation interactions were treated by The Perdew-Becke-Ernzerhof (PBE) ${ }^{3}$

functional. The projector augmented wave $(\mathrm{PAW})^{4}$ was used with a kinetic energy cutoff of $400 \mathrm{eV}$. All structures were optimized with a convergence criterion of $1 \times 10^{-}$ ${ }^{5} \mathrm{eV}$ for the energy and $0.01 \mathrm{eV} / \AA$ for the forces. The first Brillouin zone was sampled by a $3 \times 3 \times 1 \mathrm{k}$-point grid generated within the Monkhorst-Pack ${ }^{5}$ scheme.

The oxidation of hydrazine into nitrogen process is a four electron reaction involving the following elementary steps, where the symbol " "*" represented the active site.

$\mathrm{N}_{2} \mathrm{H}_{4}+* \rightarrow * \mathrm{~N}_{2} \mathrm{H}_{4}$

$* \mathrm{~N}_{2} \mathrm{H}_{4}+\mathrm{OH}^{-} \rightarrow * \mathrm{~N}_{2} \mathrm{H}_{3}+\mathrm{H}_{2} \mathrm{O}+\mathrm{e}^{-}$

$* \mathrm{~N}_{2} \mathrm{H}_{3}+\mathrm{OH}^{-} \rightarrow * \mathrm{~N}_{2} \mathrm{H}_{2}+\mathrm{H}_{2} \mathrm{O}+\mathrm{e}^{-}$

$* \mathrm{~N}_{2} \mathrm{H}_{2}+\mathrm{OH}^{-} \rightarrow * \mathrm{~N}_{2} \mathrm{H}+\mathrm{H}_{2} \mathrm{O}+\mathrm{e}^{-}$

$* \mathrm{~N}_{2} \mathrm{H}+\mathrm{OH}^{-} \rightarrow * \mathrm{~N}_{2}+\mathrm{H}_{2} \mathrm{O}+\mathrm{e}^{-}$

$* \mathrm{~N}_{2}+\mathrm{OH}^{-} \rightarrow \mathrm{N}_{2}+*$

The free energy diagrams of the hydrazine oxidation reaction $(\mathrm{HzOR})$ have been calculated according to the computational hydrogen electrode method ${ }^{6}$. Free energy change from initial states to final states of the reaction is calculated as follows:

$\Delta \mathrm{G}=\Delta \mathrm{E}+(\Delta \mathrm{ZPE}-\mathrm{T} \Delta \mathrm{S})$

where $\Delta \mathrm{E}$ is the adsorption or reaction energy based on DFT calculations, $\triangle \mathrm{ZPE}$ is the change in zero-point energy, $\mathrm{T}$ is the temperature $(298.15 \mathrm{~K})$, and $\Delta \mathrm{S}$ is the change in entropy. The entropies of gas phase $\mathrm{N}_{2}, \mathrm{H}_{2}$, and $\mathrm{N}_{2} \mathrm{H}_{4}$ are obtained from the National Institute of Standards and Technology database ${ }^{7}$ with the standard condition.

The work function $(\Phi)$ is defined as the energy difference between the vacuum and $\mathrm{E}_{\mathrm{F}}, \Phi=\mathrm{E}_{\mathrm{vac}}-\mathrm{E}_{\mathrm{F}}$, where $\mathrm{E}_{\mathrm{vac}}$ is the vacuum level and $\mathrm{E}_{\mathrm{F}}$ is Fermi level. $\mathrm{E}_{\mathrm{vac}}$ is obtained using the planar-average electrostatic potential energy along the $\mathrm{z}$ direction (vacuum direction).

\section{Supplementary Figures and Tables}



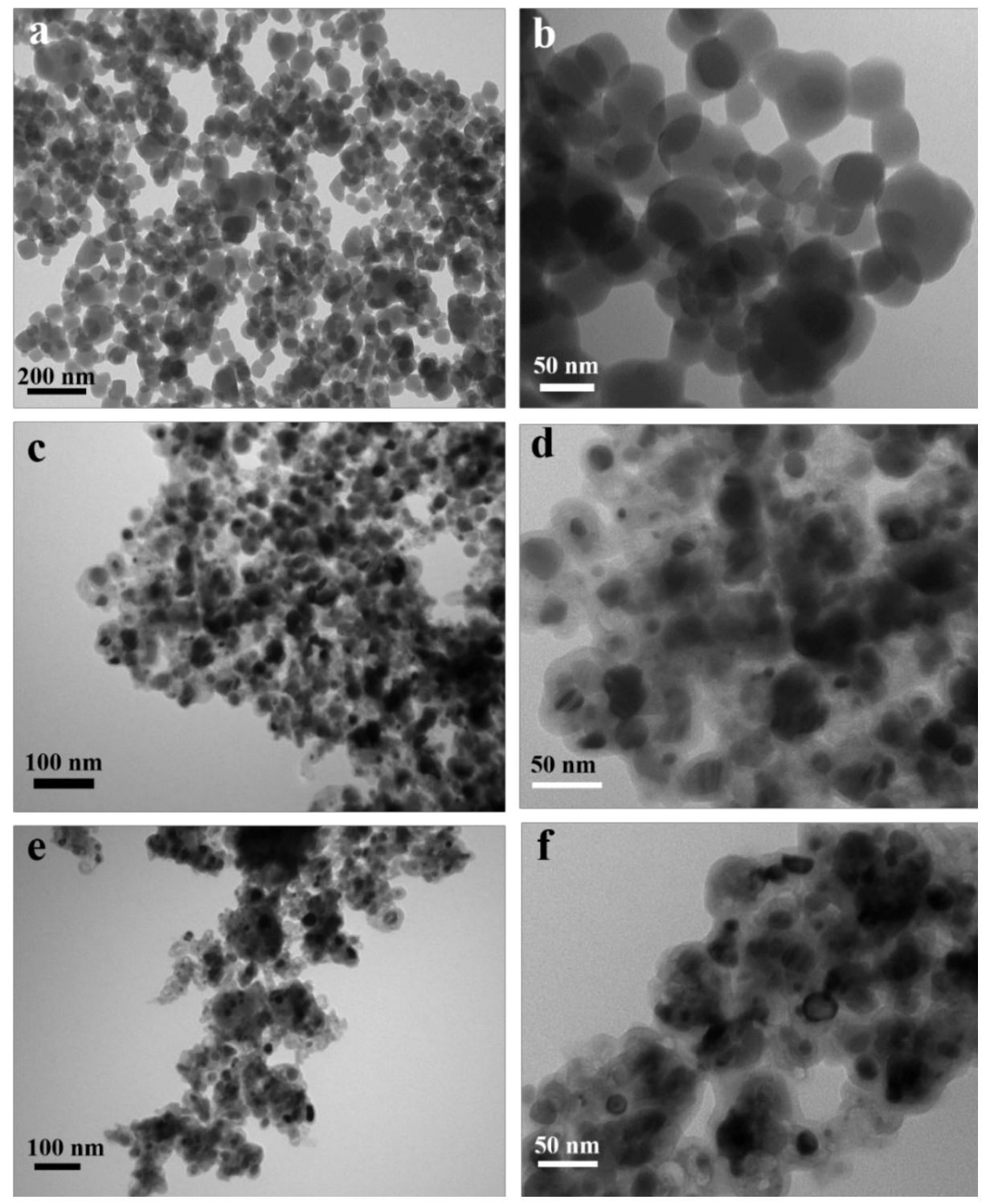

Figure S1. TEM images of the as-prepared (a) and (b) $\mathrm{Co}_{3}\left[\mathrm{Co}(\mathrm{CN})_{6}\right]_{2}$; (c) and (d) $\mathrm{Co} N P s$, and (e) and (f) $\mathrm{CoP} / \mathrm{Co}-20$. 


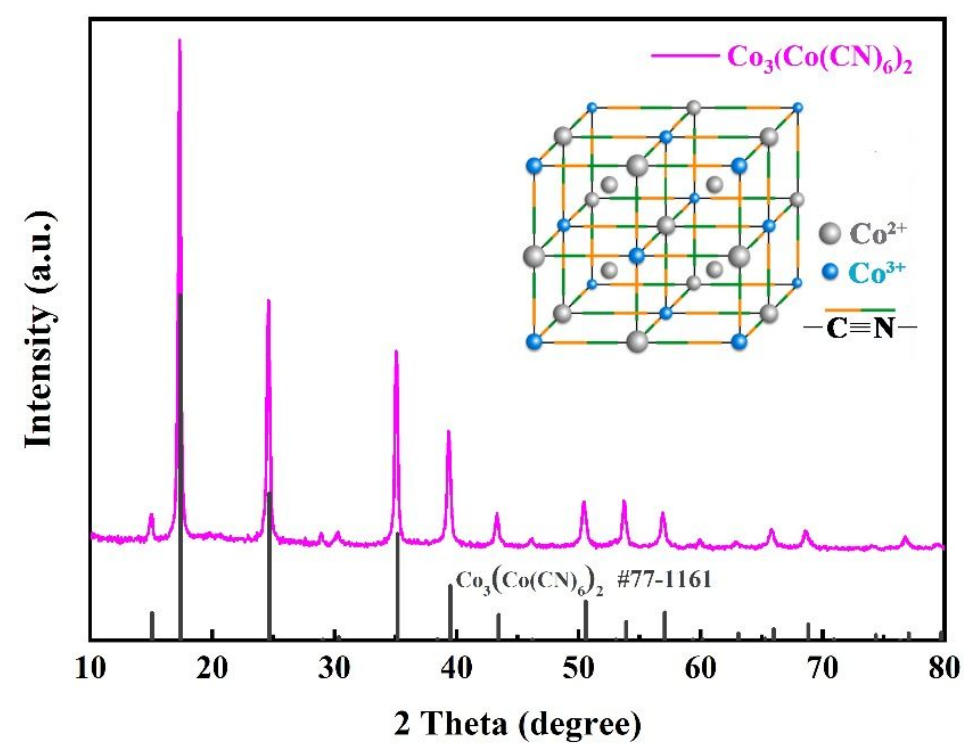

Figure S2. XRD patterns of the as-prepared $\mathrm{Co}_{3}\left[\mathrm{Co}(\mathrm{CN})_{6}\right]_{2}$.

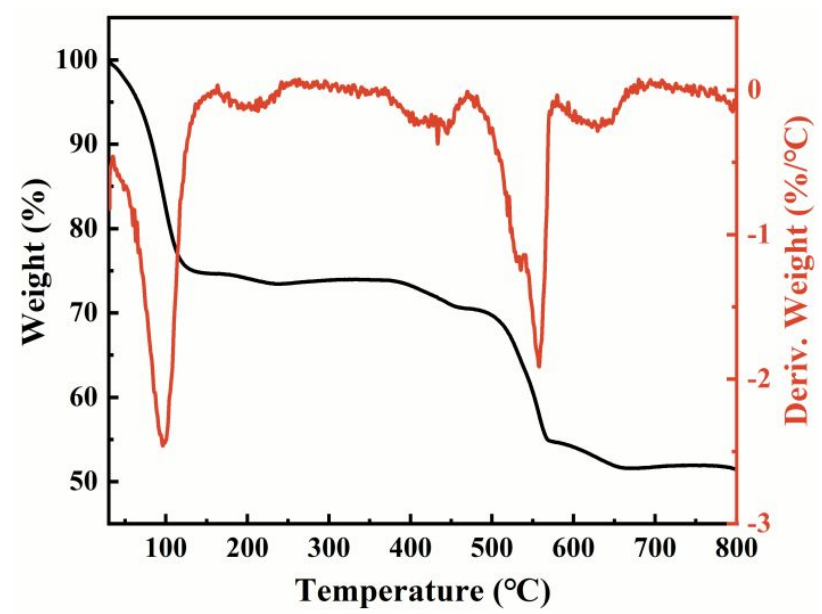

Figure S3. TGA/DTG curves of as-prepared $\mathrm{Co}_{3}\left[\mathrm{Co}(\mathrm{CN})_{6}\right]_{2}$. under nitrogen atmosphere with a heating rate of $10^{\circ} \mathrm{C} \mathrm{min}^{-1}$.
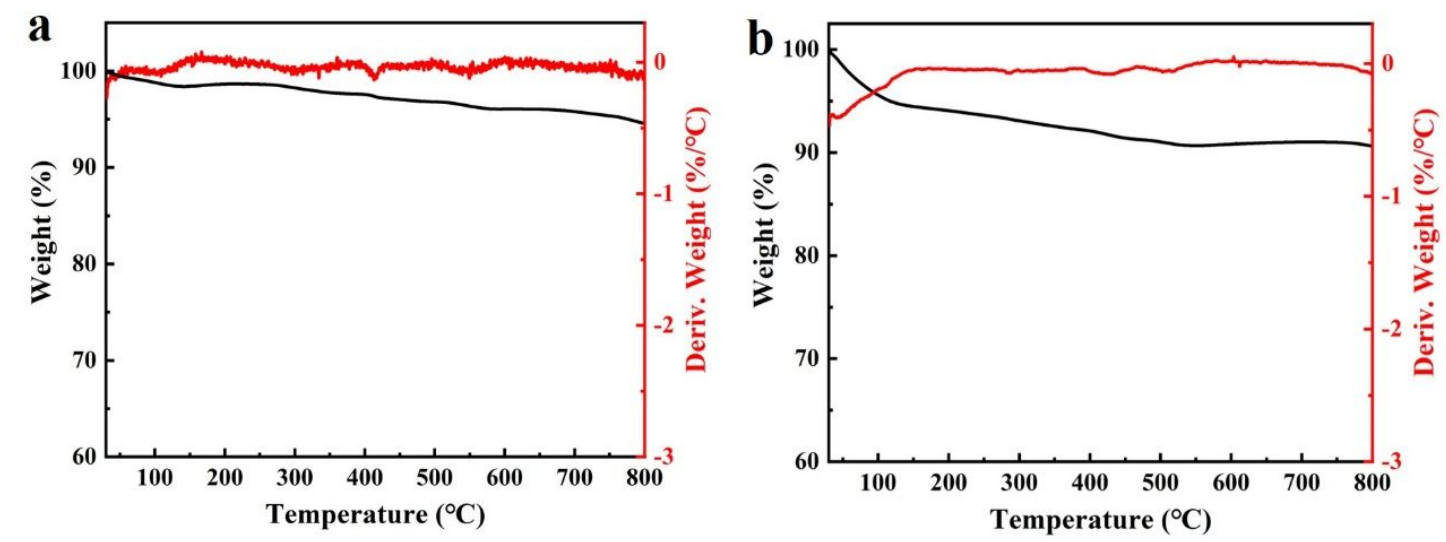

Figure S4. TGA/DTG curves of as-prepared Co NPs (a) and CoP/Co-20 (b) under nitrogen atmosphere with a heating rate of $10^{\circ} \mathrm{C} \mathrm{min}^{-1}$. 

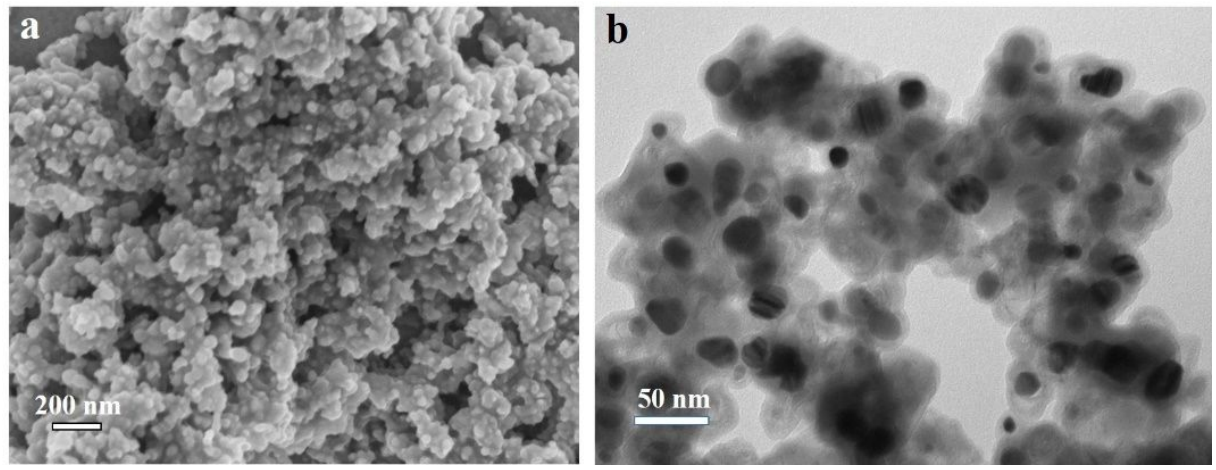

Figure S5. (a) and (b) FESEM and TEM images of the CoP/Co-5.
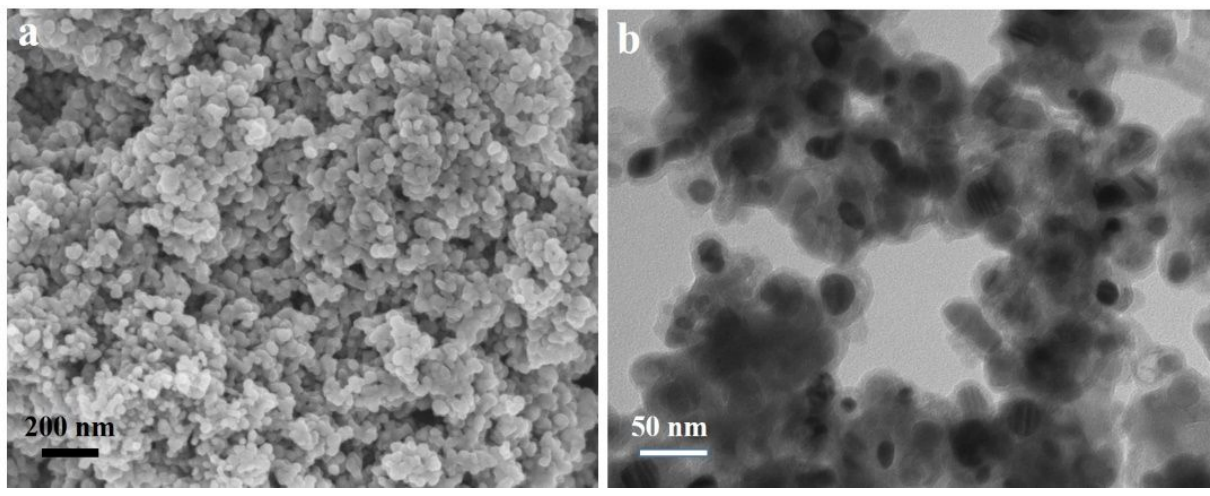

Figure S6. (a) and (b) FESEM and TEM images of the CoP/Co-10.
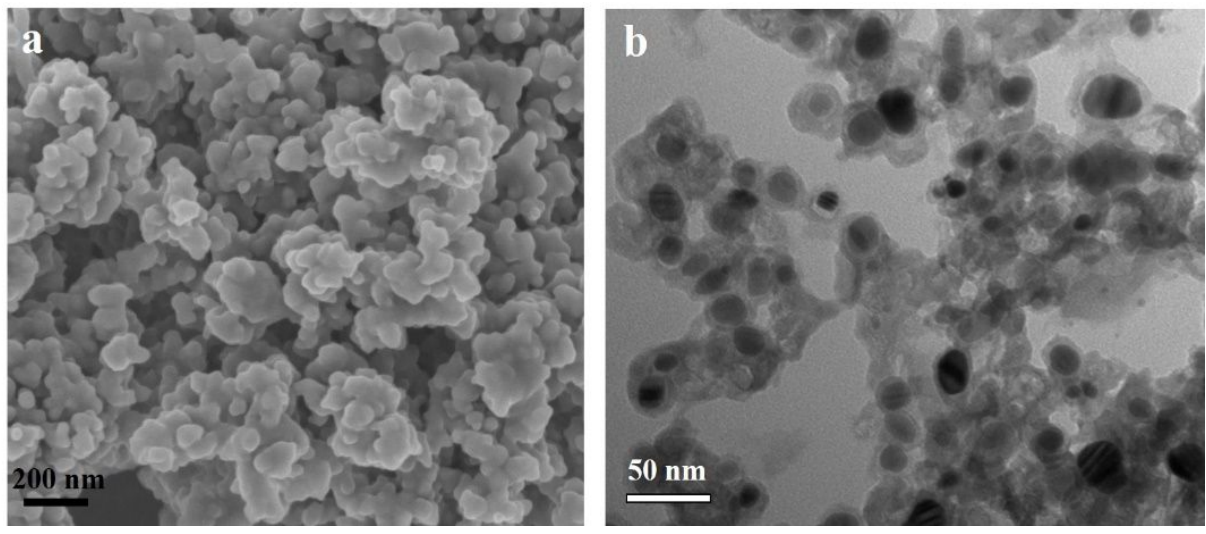

Figure S7. (a) and (b) FESEM and TEM images of the CoP/Co-30.
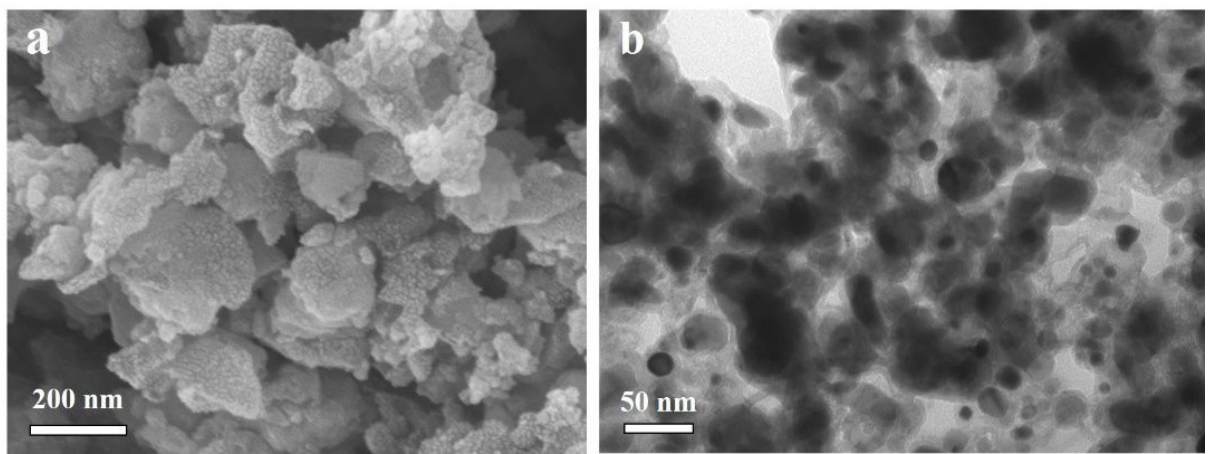

Figure S8. (a) and (b) FESEM and TEM images of the CoP. 


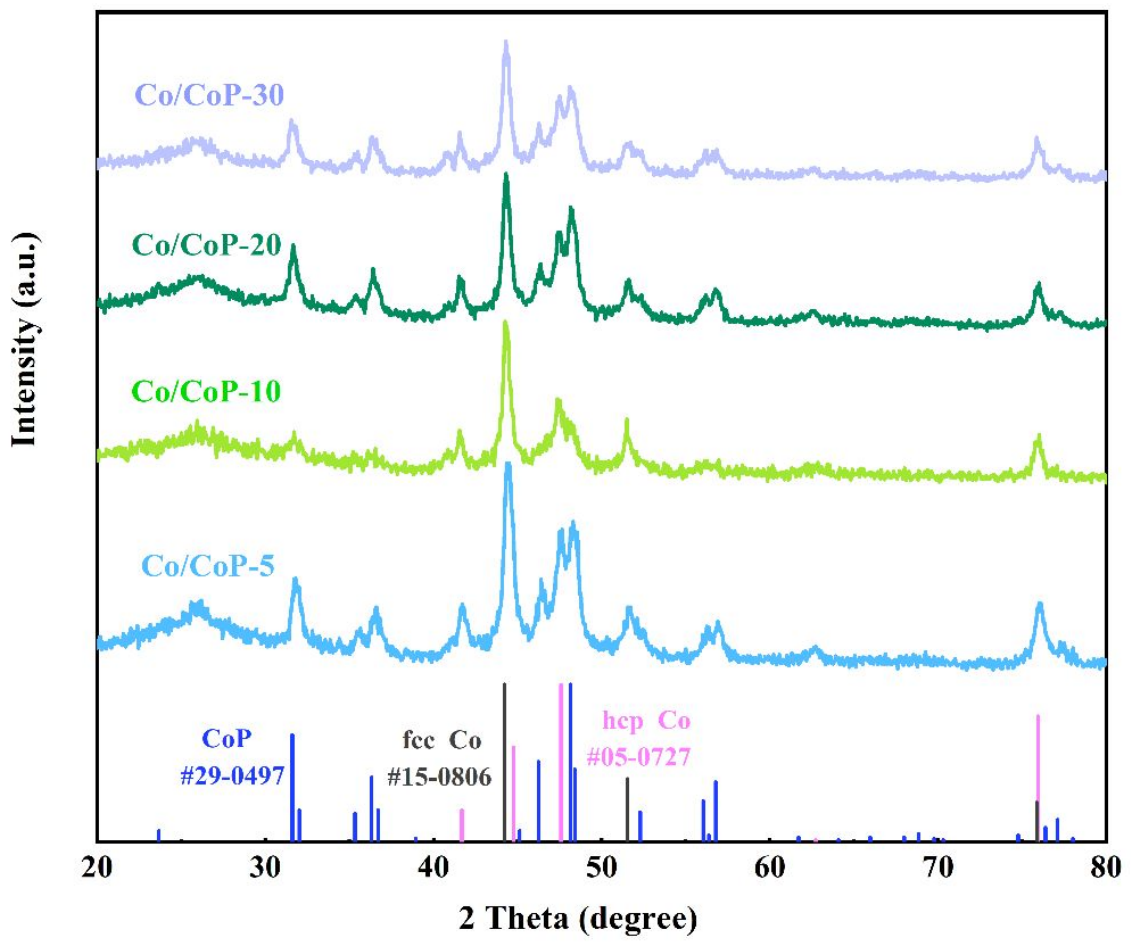

Figure S9. Typical XRD patterns of CoP/Co-5, CoP/Co-10, CoP/Co-20, and CoP/Co-30.

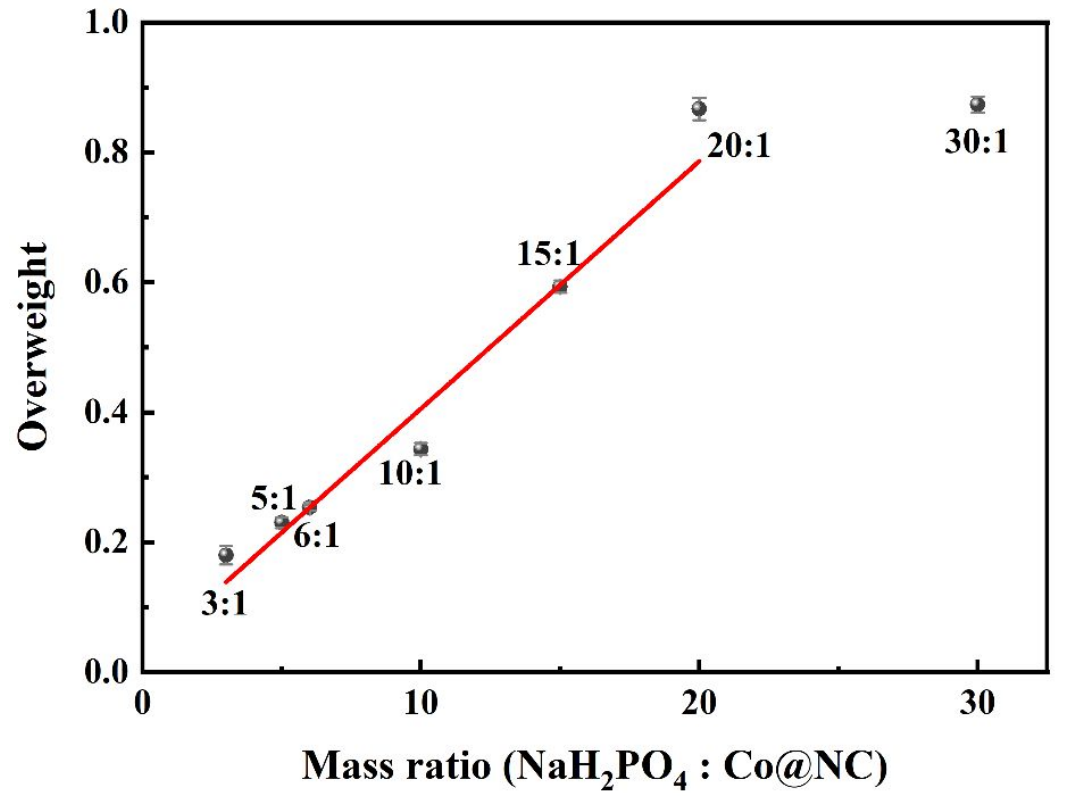

Figure S10. Weight gain curves for phosphating with different mass ratios of $\mathrm{NaH}_{2} \mathrm{PO}_{2} \cdot \mathrm{H}_{2} \mathrm{O}$ and Co NPs. 


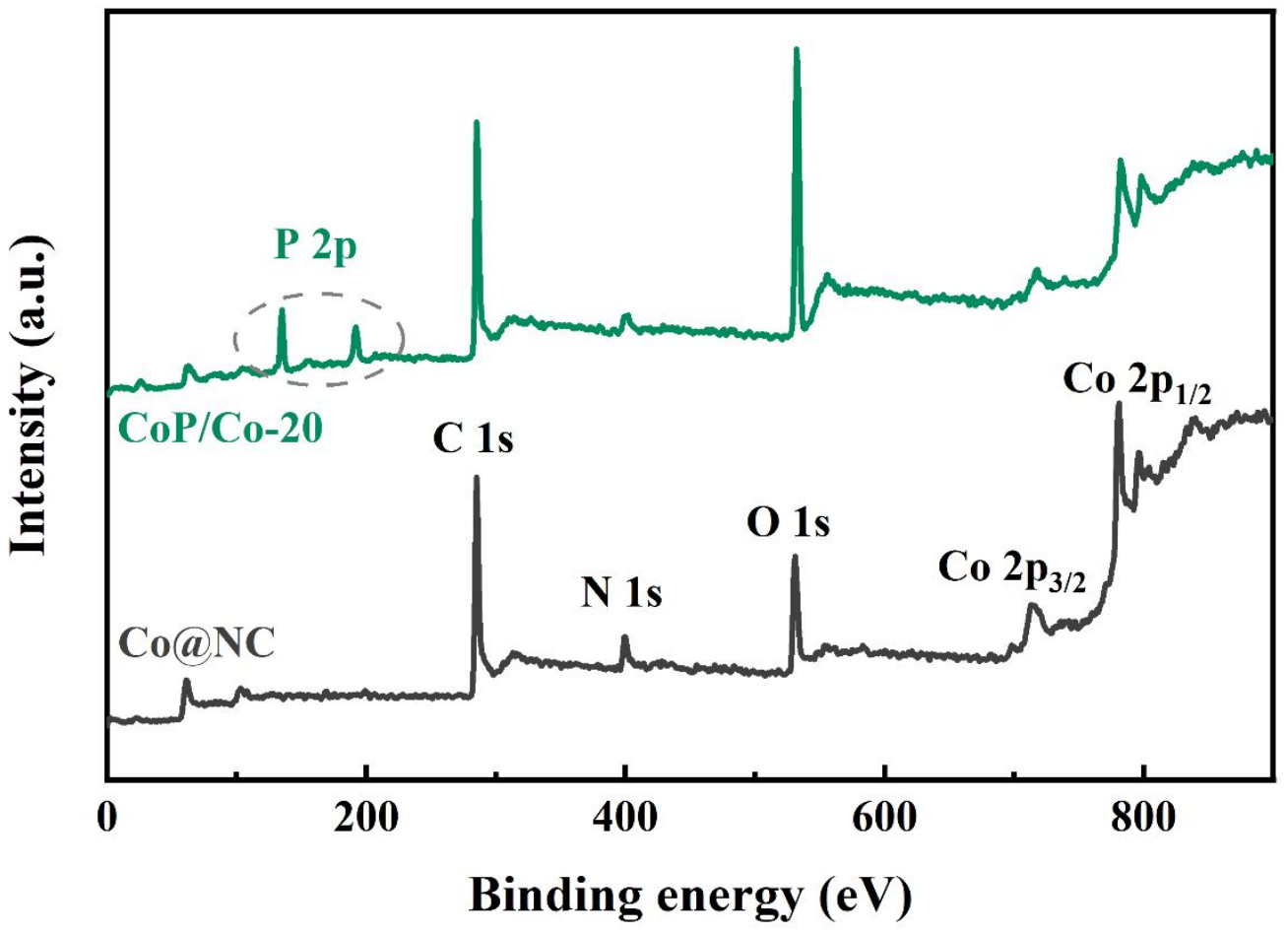

Figure S11. XPS survey spectrum of CoP/Co-20 and Co NPs.

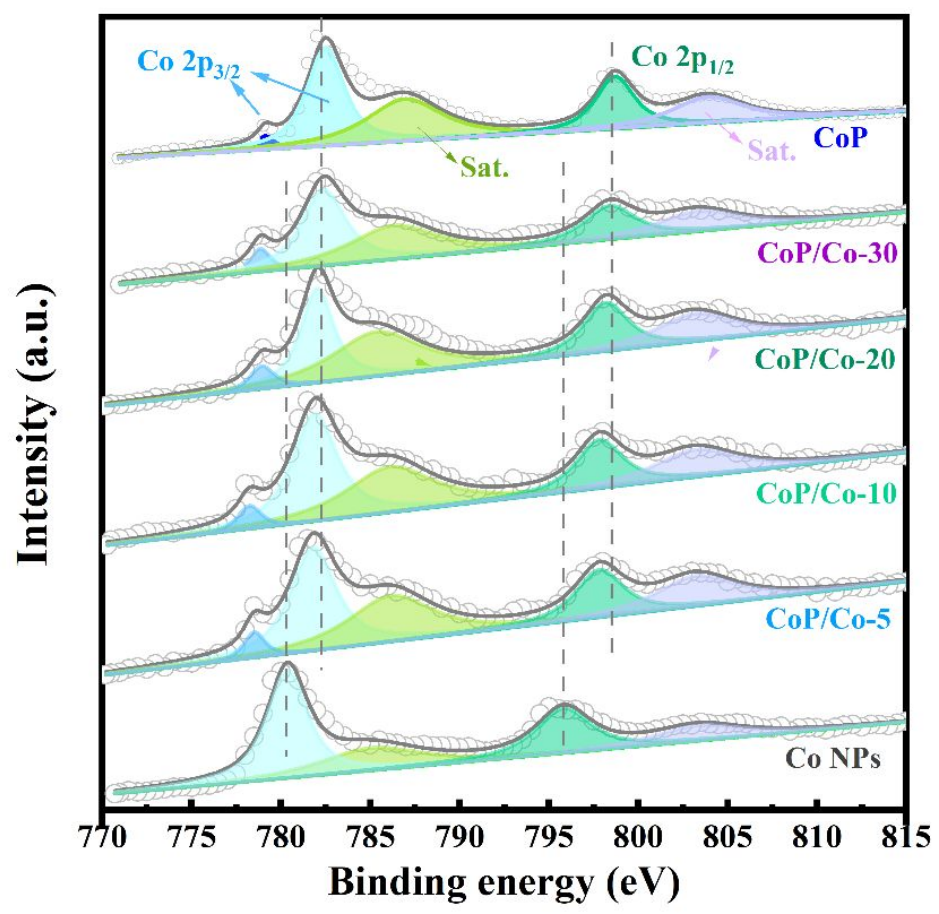

Figure S12. High-resolution spectra of XPS of Co NPs, CoP and CoP/Co-n samples for Co 2p. 


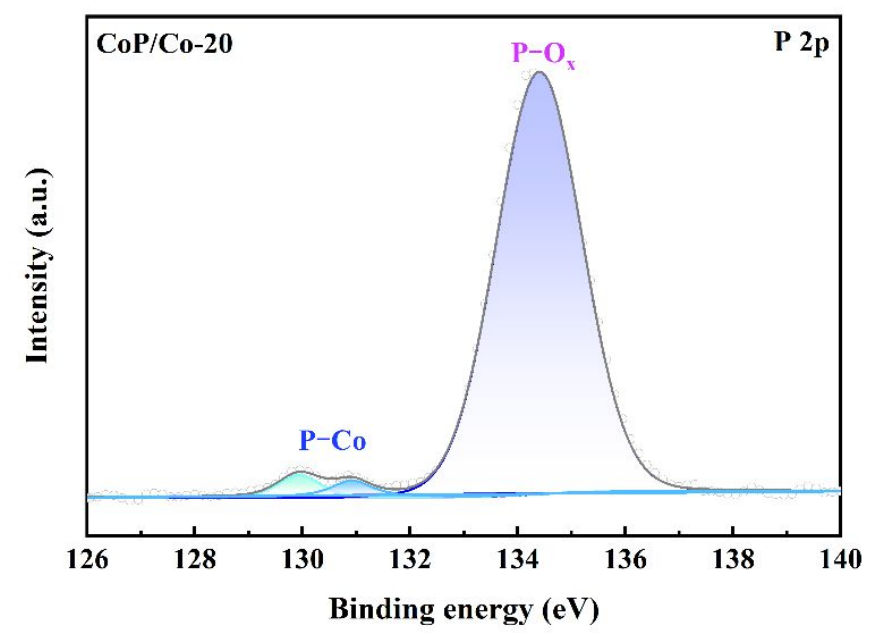

Figure S13. High-resolution spectra of XPS of CoP/Co-20 for P 2p.
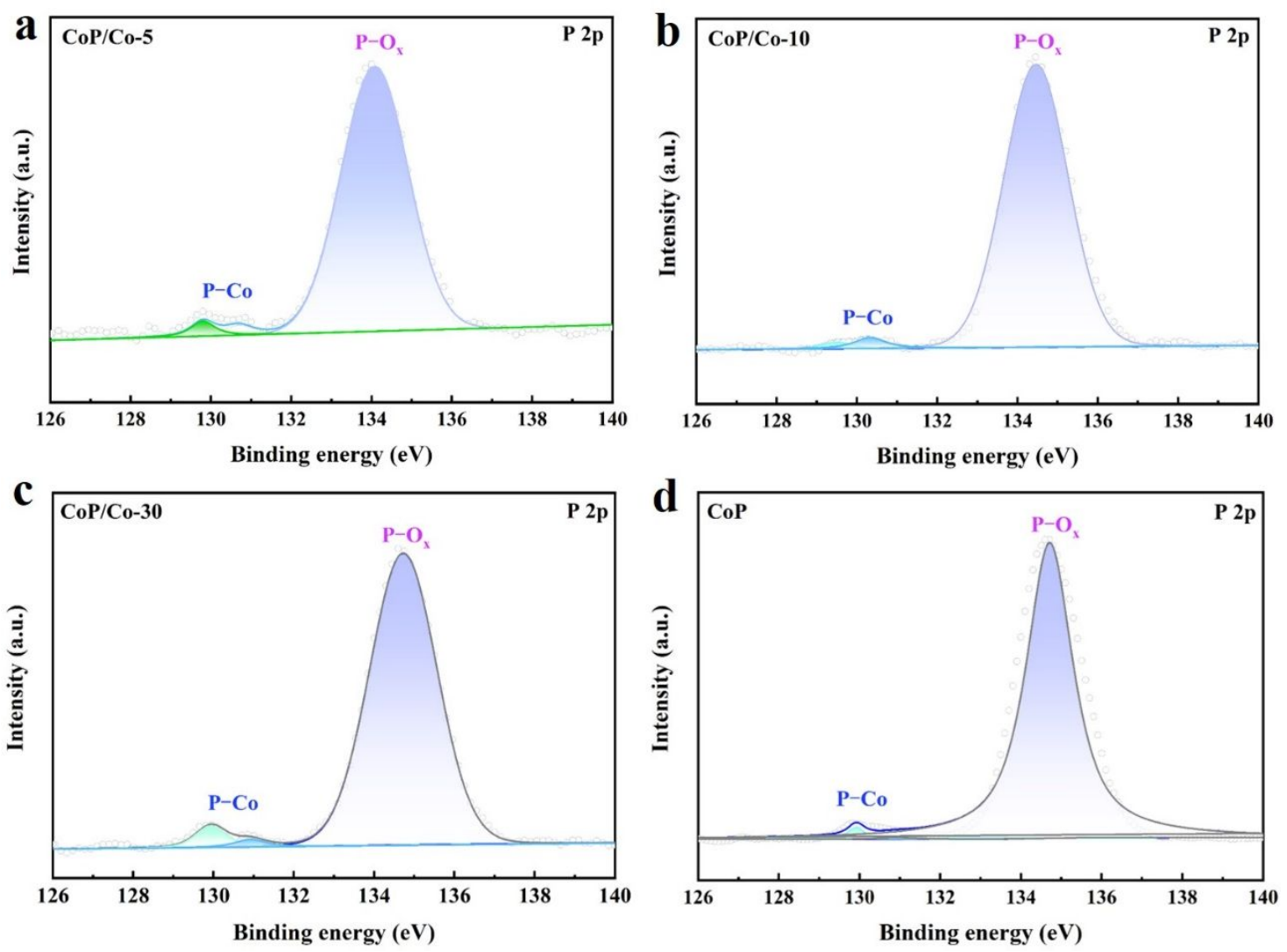

Figure S14. High-resolution spectra of XPS of CoP/Co-n for P 2p.(a) CoP/Co-5; (b) CoP/Co-10; (c) $\mathrm{CoP} / \mathrm{Co}-30$; (d) $\mathrm{CoP}$. 


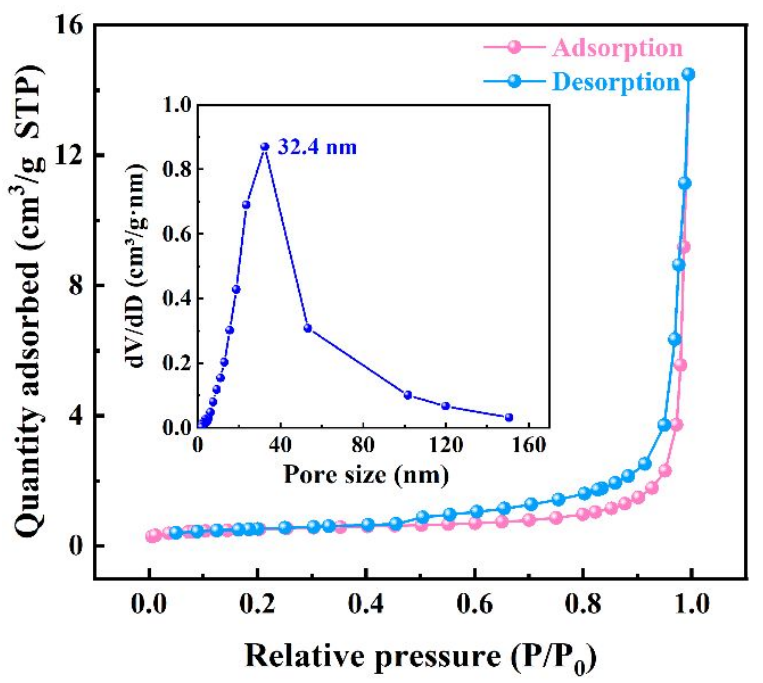

Figure S15. $\mathrm{N}_{2}$ adsorption/desorption isotherms of $\mathrm{CoP} / \mathrm{Co}-20$ sample (inset for pore size distribution plot).
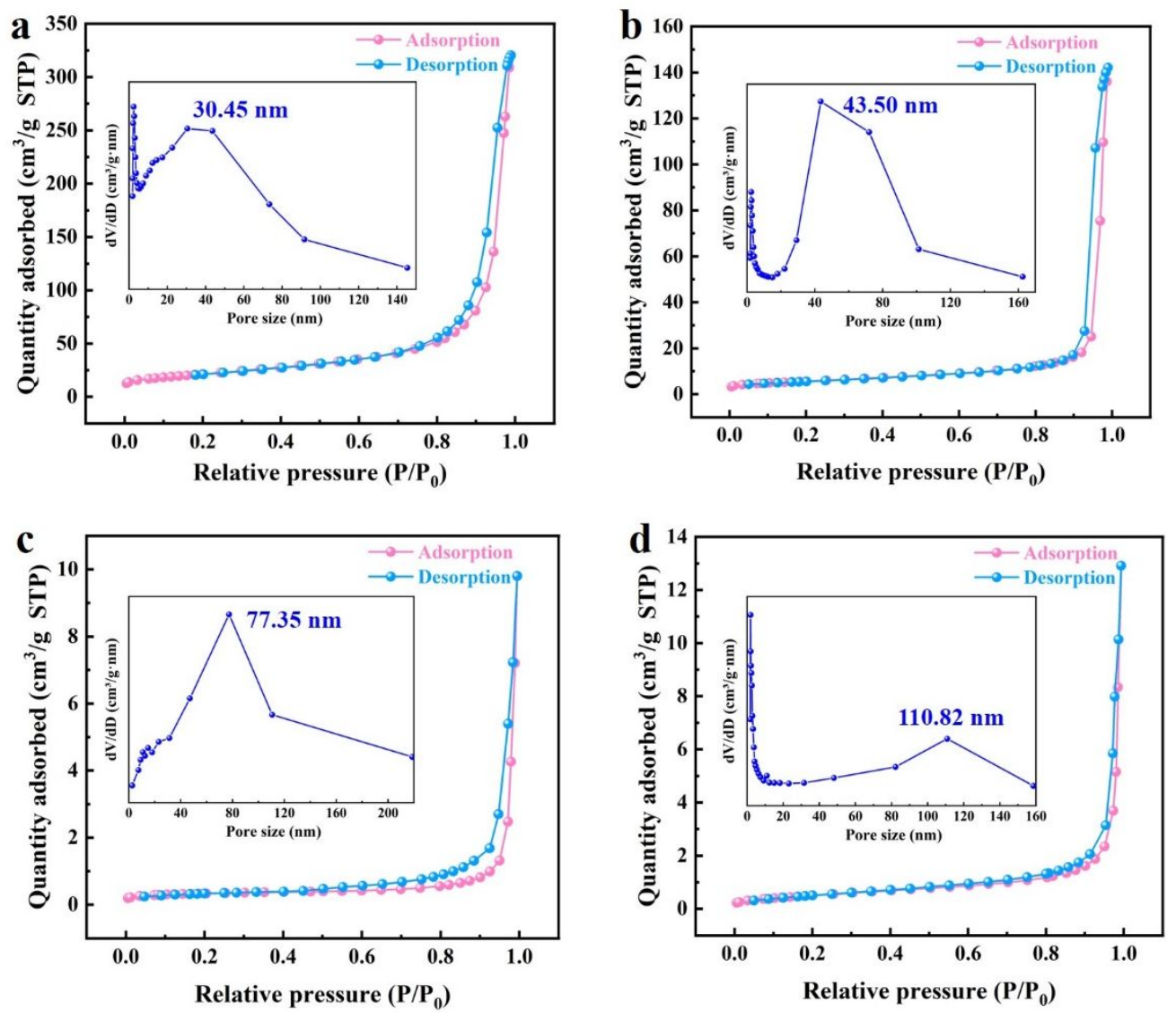

Figure S16. $\mathrm{N}_{2}$ adsorption/desorption isotherms of Co NPs and CoP/Co-n samples (inset for pore size distribution plot). (a) Co NPs; (b) $\mathrm{CoP} / \mathrm{Co}-5$; (c) $\mathrm{CoP} / \mathrm{Co}-10$; (d) $\mathrm{CoP} / \mathrm{Co}-30$. 


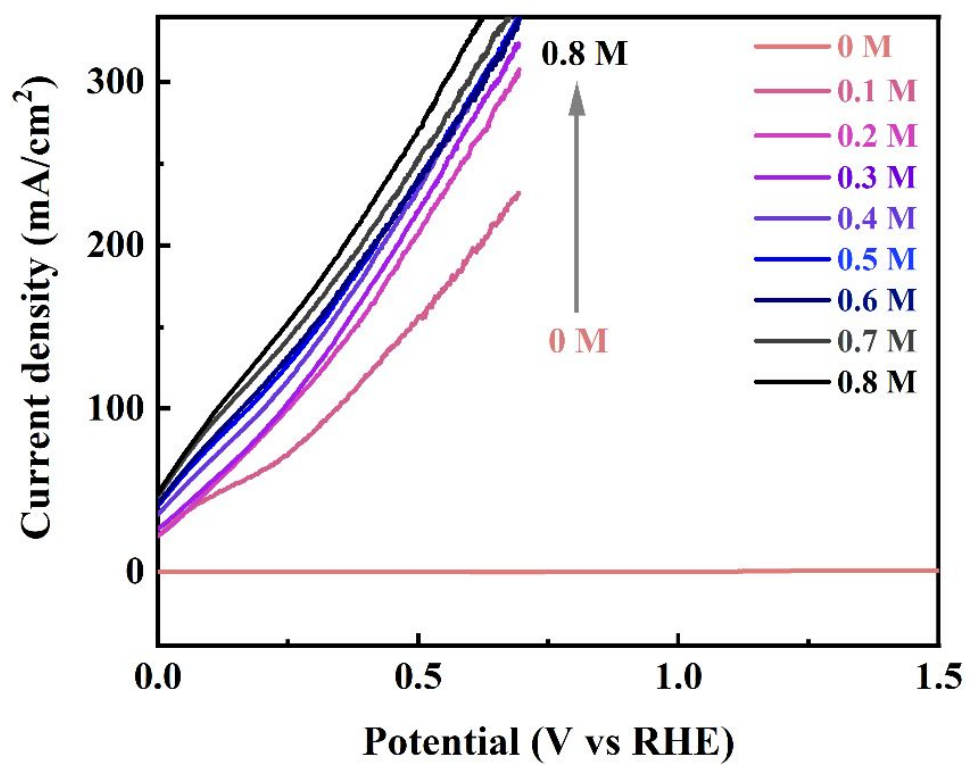

Figure S17. Hydrazine oxidation LSV polarization curves of CoP/Co-20 in $1.0 \mathrm{M} \mathrm{KOH}$ containing different hydrazine concentrations. 

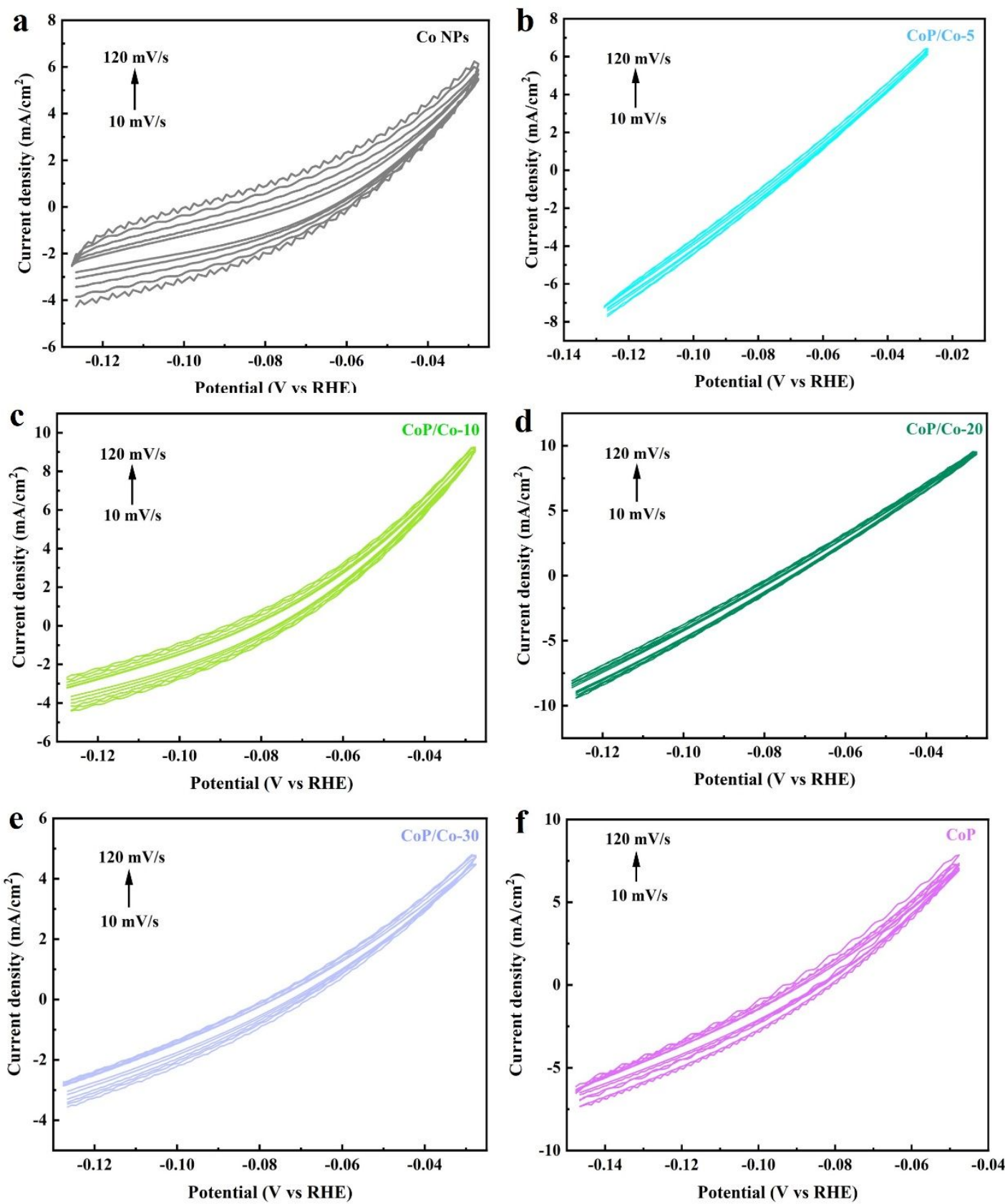

Figure S18. CV curves measured within the range of -0.127 to $-0.027 \mathrm{~V} v s$. RHE with scan rate from 10 to $120 \mathrm{mV} \mathrm{s}^{-1}$ of Co NPs and CoP/Co-n samples. (a) Co NPs; (b) CoP/Co-5; (c) CoP/Co10; (d) $\mathrm{CoP} / \mathrm{Co}-20$; (e) $\mathrm{CoP} / \mathrm{Co}-30$. (f) $\mathrm{CoP}$. 


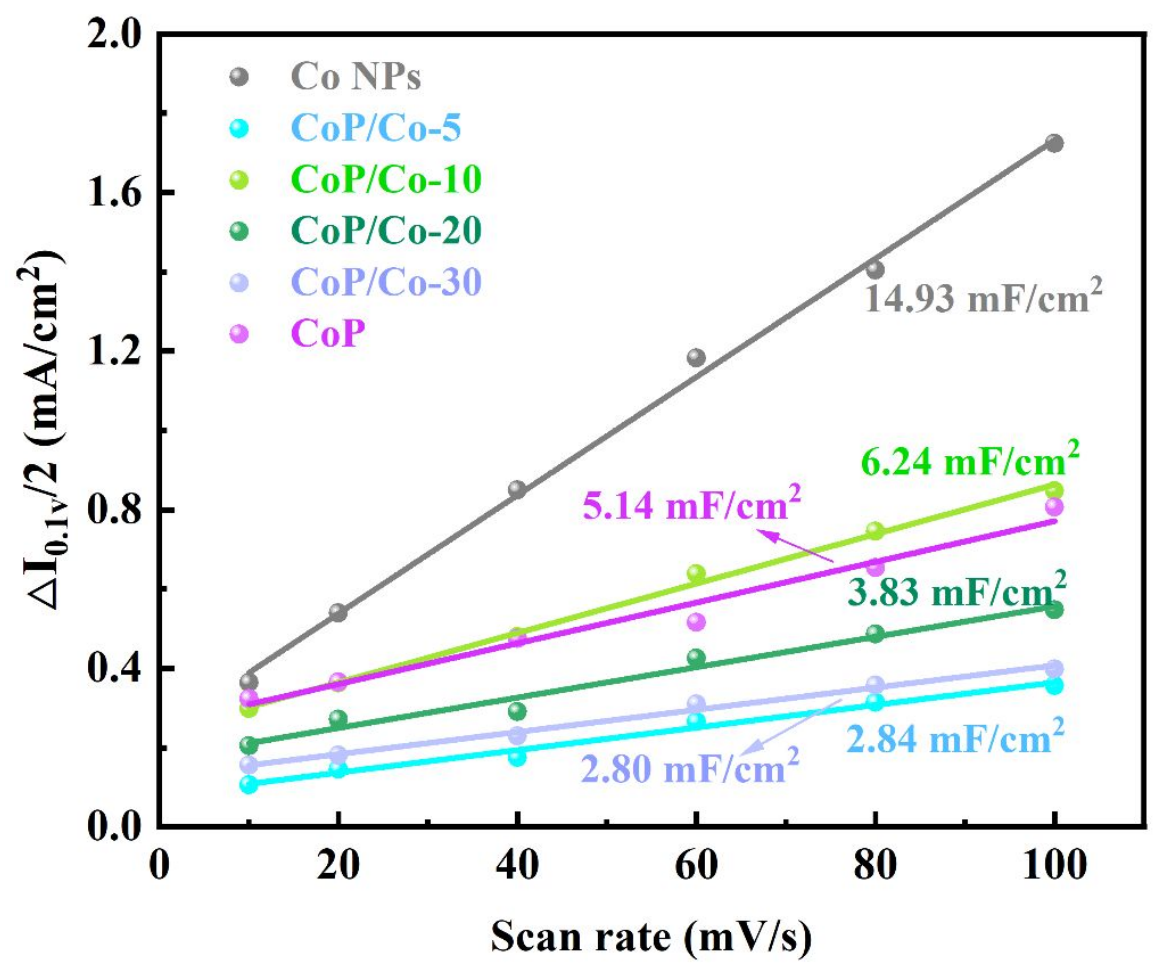

Figure S19. $\mathrm{C}_{\mathrm{dl}}$ values estimated through linear fitting of the scan rate of $\mathrm{Co} \mathrm{NPs}, \mathrm{CoP}$ and $\mathrm{CoP} / \mathrm{Co}-$ n samples. 

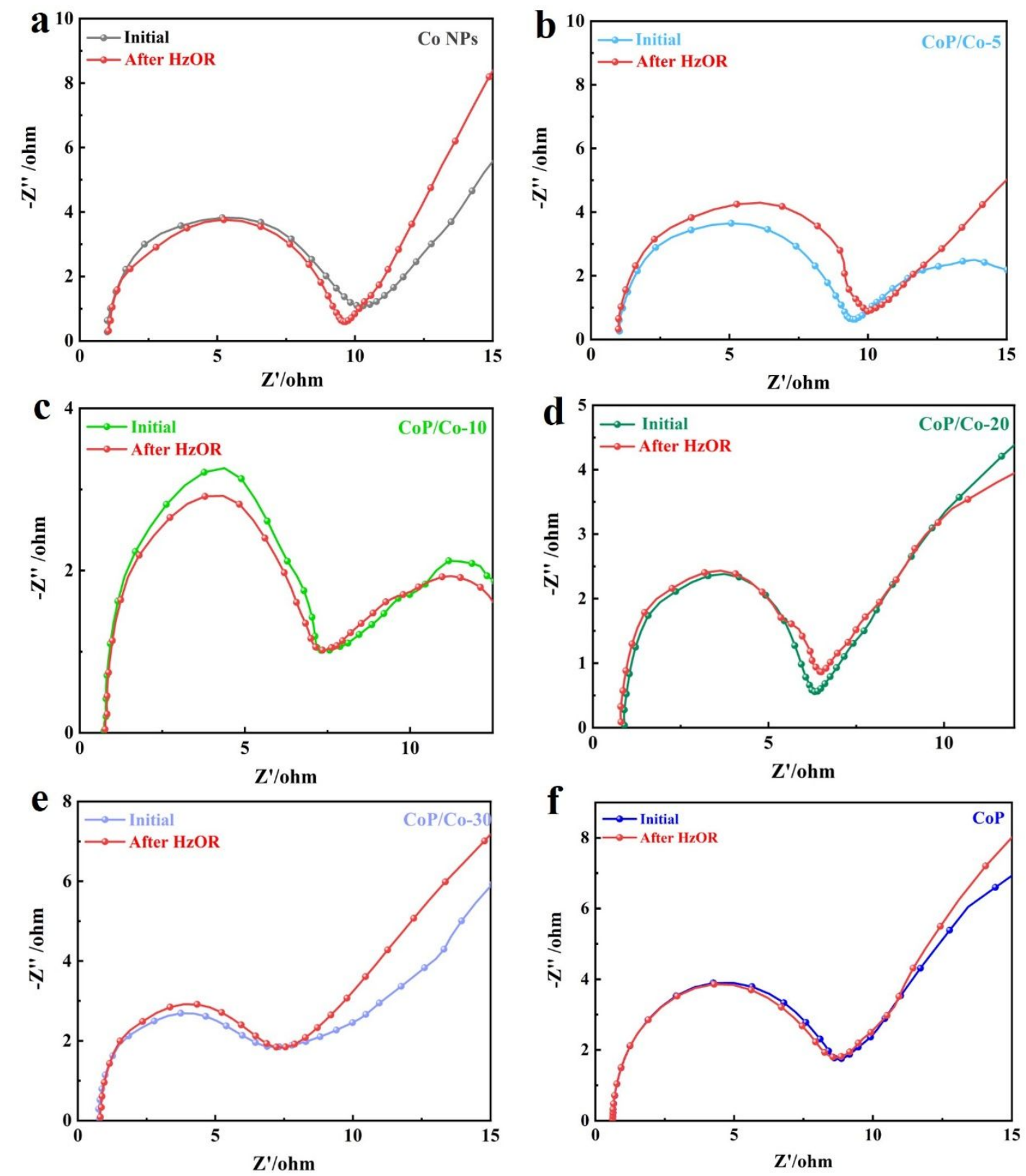

Figure S20. Electrochemical impedance spectroscopy (EIS) for Co NPs and CoP/Co-n samples before and after HzOR tests. (a) Co NPs; (b) CoP/Co-5; (c) CoP/Co-10; (d) CoP/Co-20; (e) CoP/Co30. (f) CoP. 


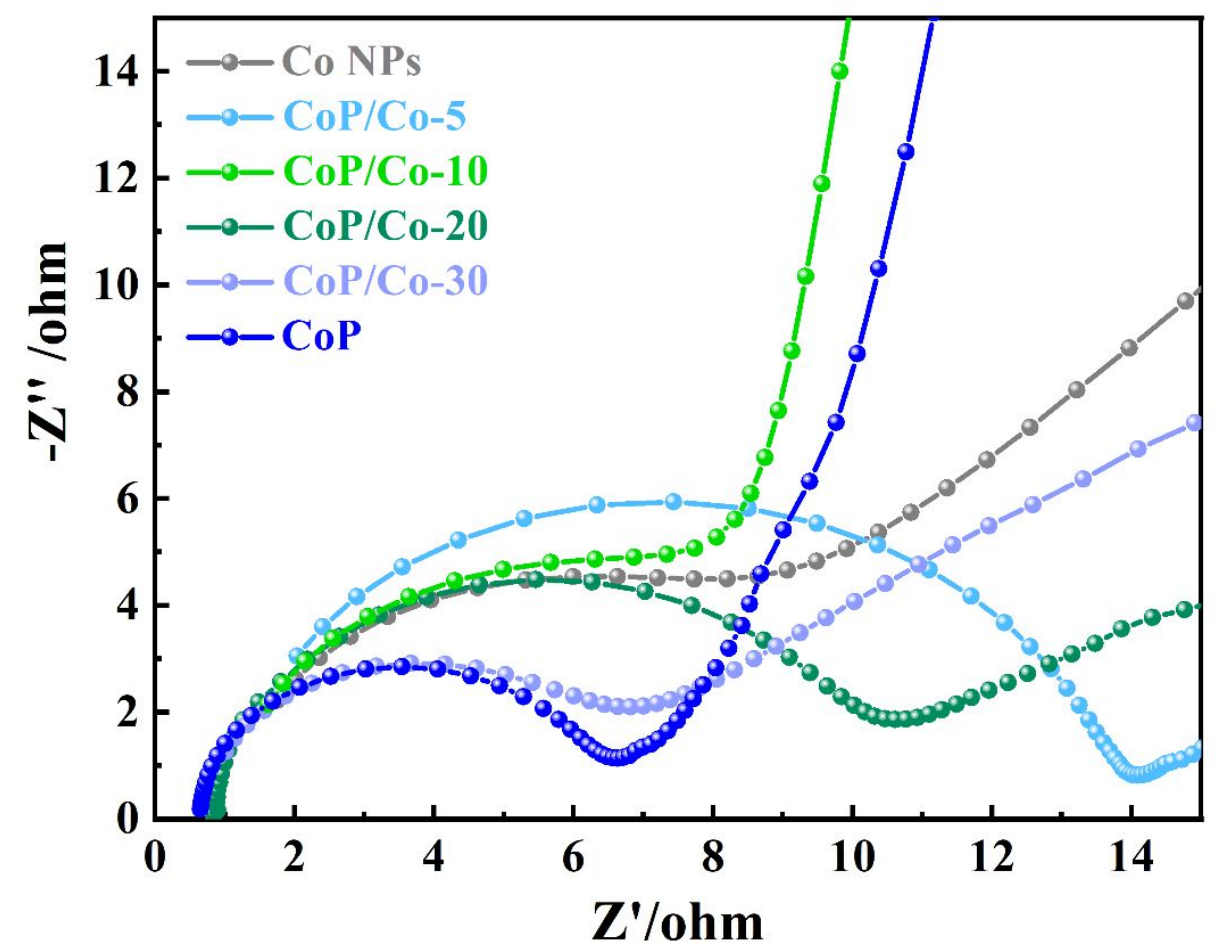

Figure S21. Electrochemical impedance spectroscopy (EIS) for Co NPs, CoP and CoP/Co-n samples in $1.0 \mathrm{M} \mathrm{KOH}$ without hydrazine.
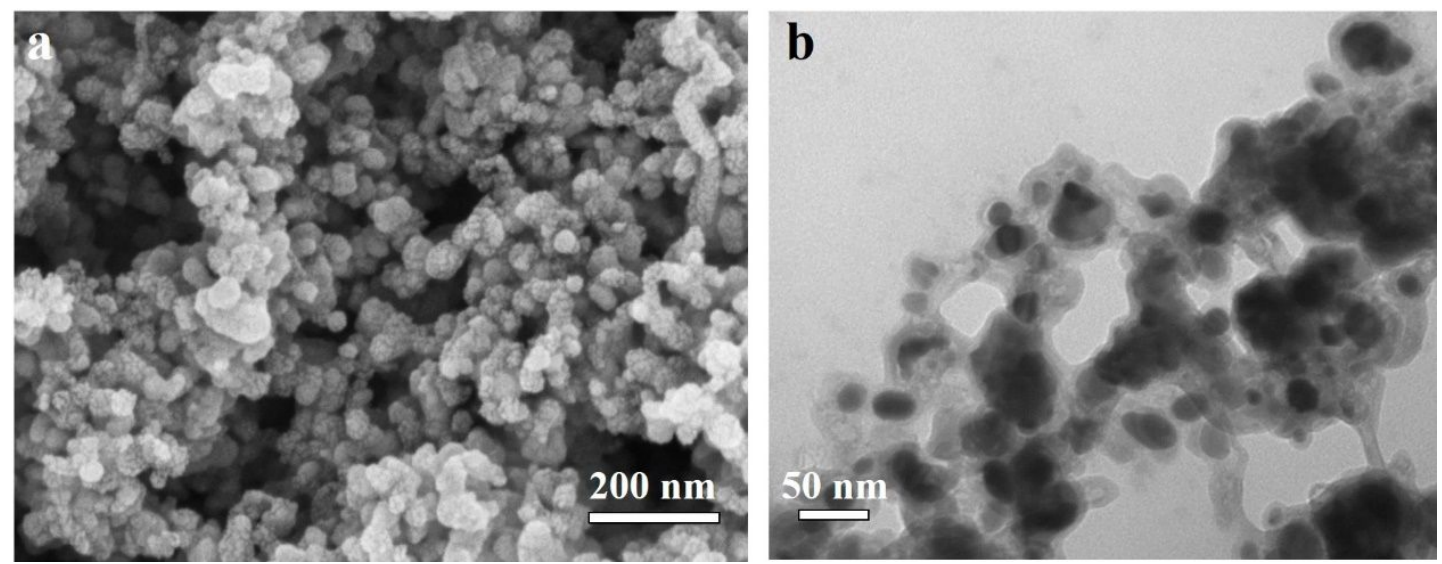

Figure S22. The FESEM and TEM images of CoP/Co-20 after stability test. (a) FESEM, and (b) TEM. 


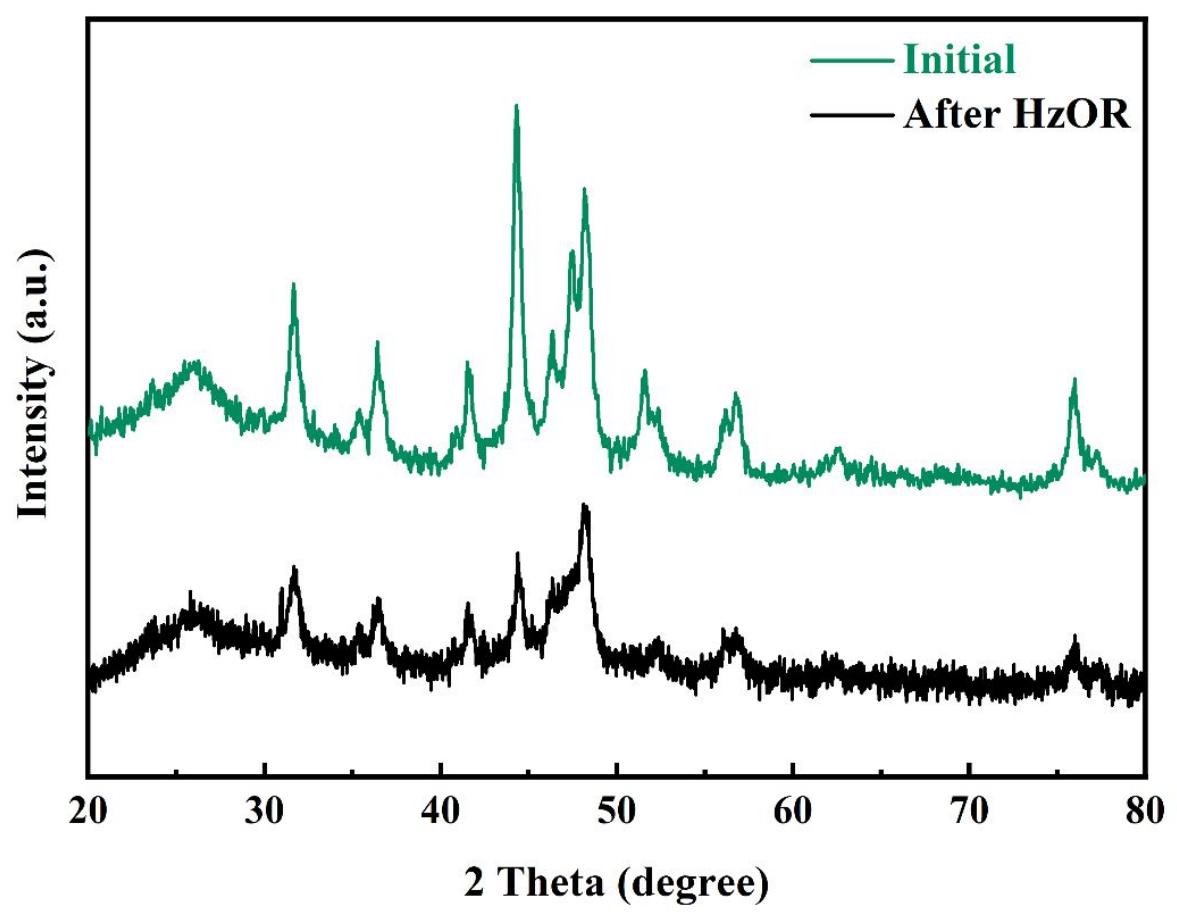

Figure S23. The XRD patterns of $\mathrm{CoP} / \mathrm{Co}-20$ between and after stability test.
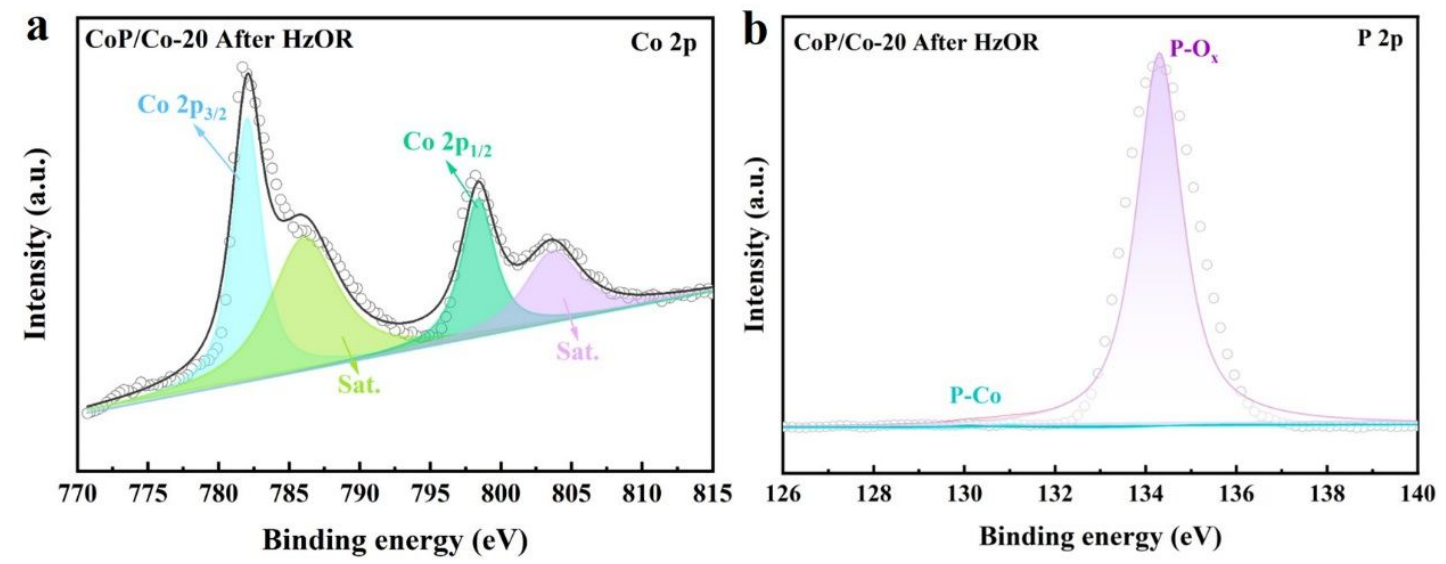

Figure S24. High-resolution spectra of XPS of CoP/Co-20 for (a) Co 2p; (b) P 2p.

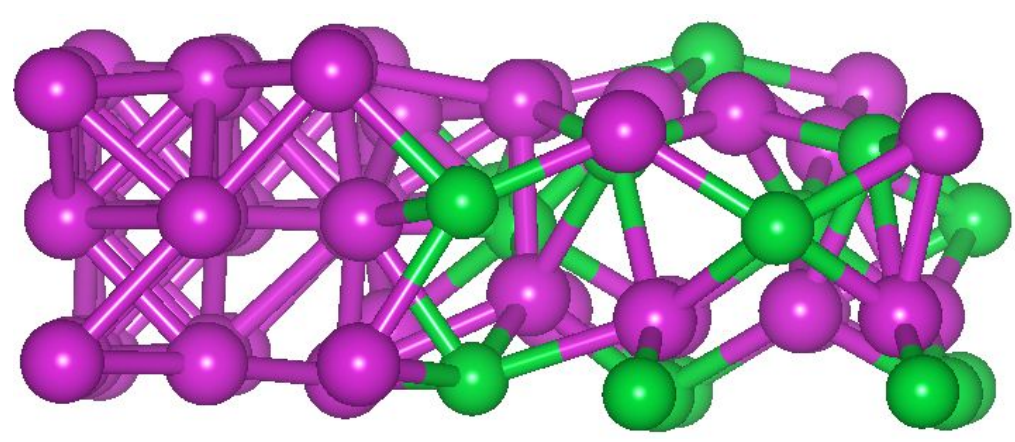

Figure S25. The model of the $\mathrm{CoP} / \mathrm{Co}$ heterostructure, the pink and green balls represent $\mathrm{Co}$ and $\mathrm{P}$ atoms, respectively. 


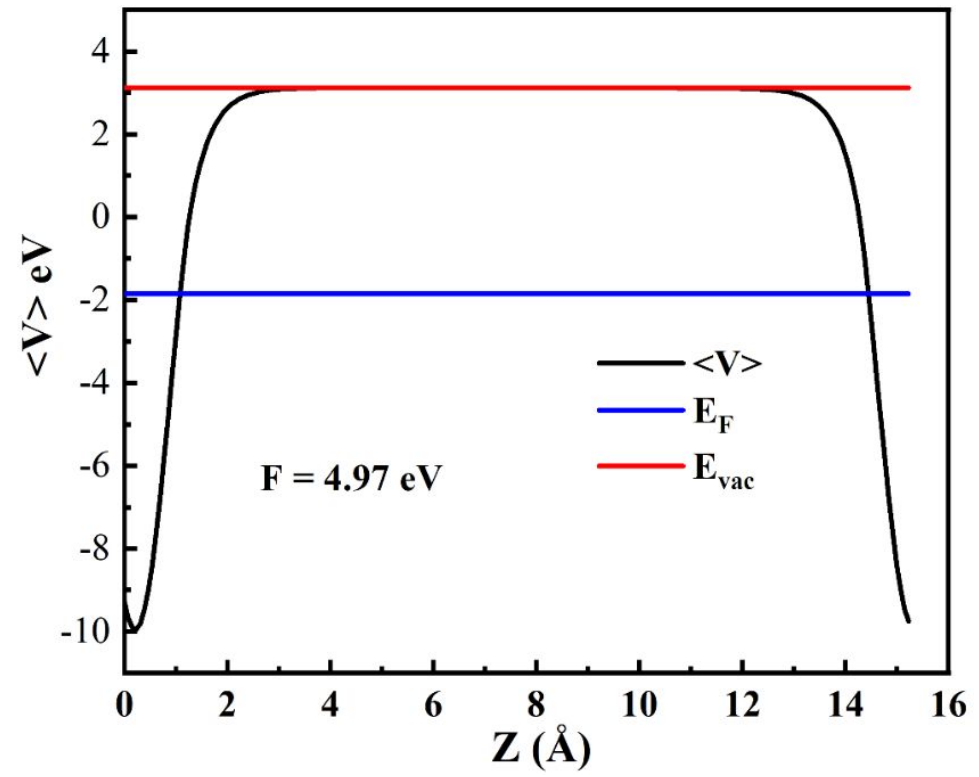

Figure S26. The electrostatic potential (V) averaged over the $x y$ plane as function of the vacuum direction $z(\AA)$ for Co (100) surface.

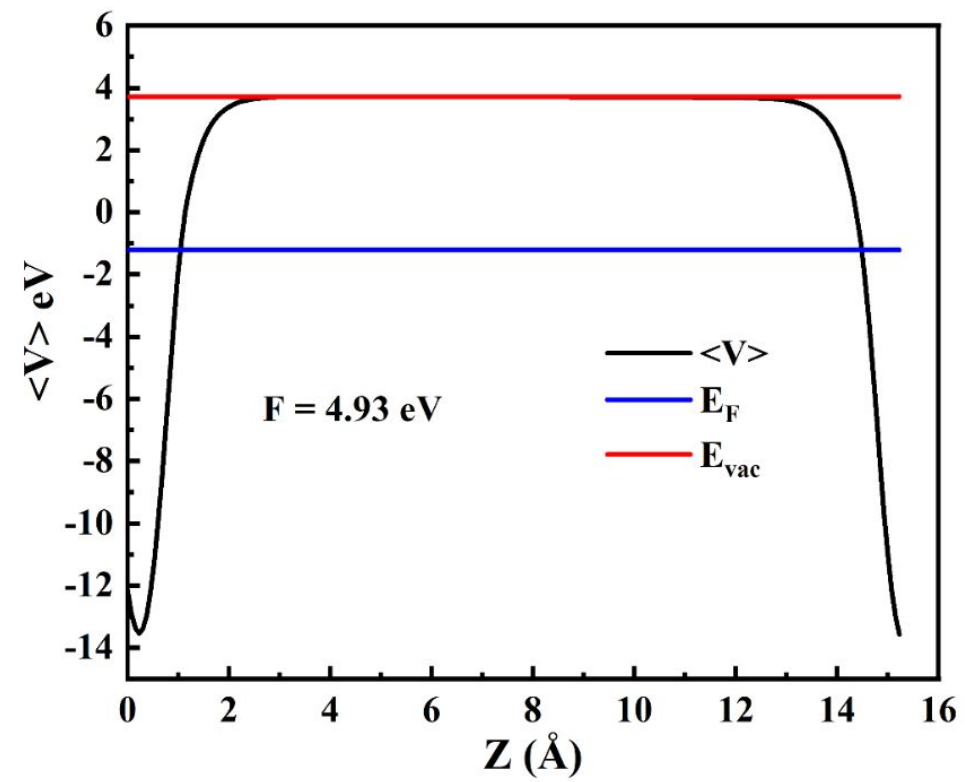

Figure S27. The electrostatic potential $(\mathrm{V})$ averaged over the $x y$ plane as function of the vacuum direction $z(\AA)$ for CoP $(100)$ surface. 


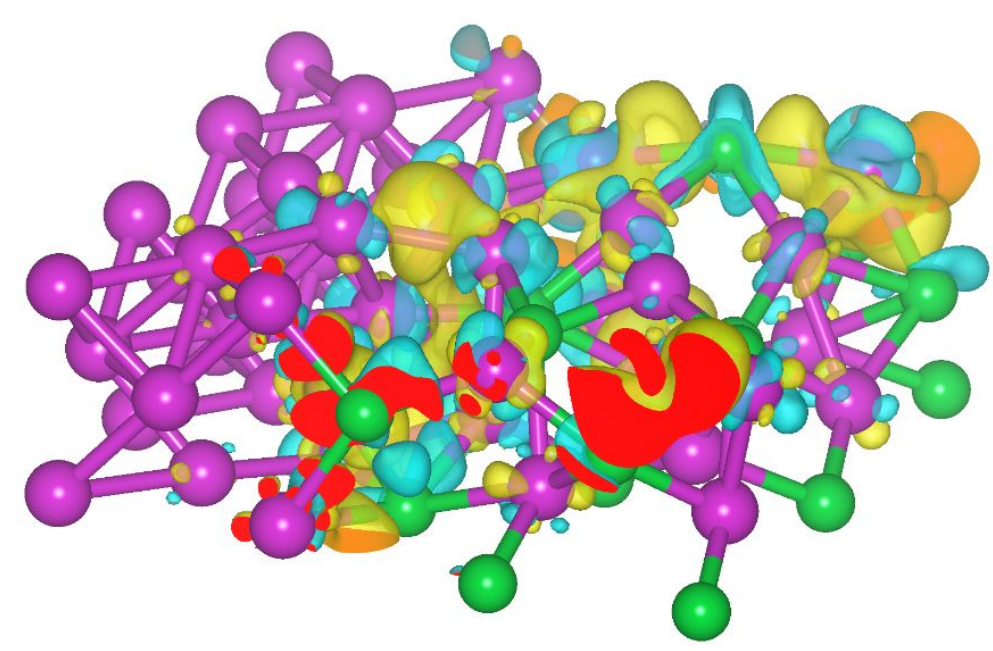

Figure S28. The electron density distribution of the $\mathrm{CoP} / \mathrm{Co}$ heterostructure, the yellow and cyan regions represent charge accumulation and depletion. The isovalues are $0.005 \mathrm{eV} / \AA 3$. The pink and green balls represent $\mathrm{Co}$ and $\mathrm{P}$ atoms, respectively.

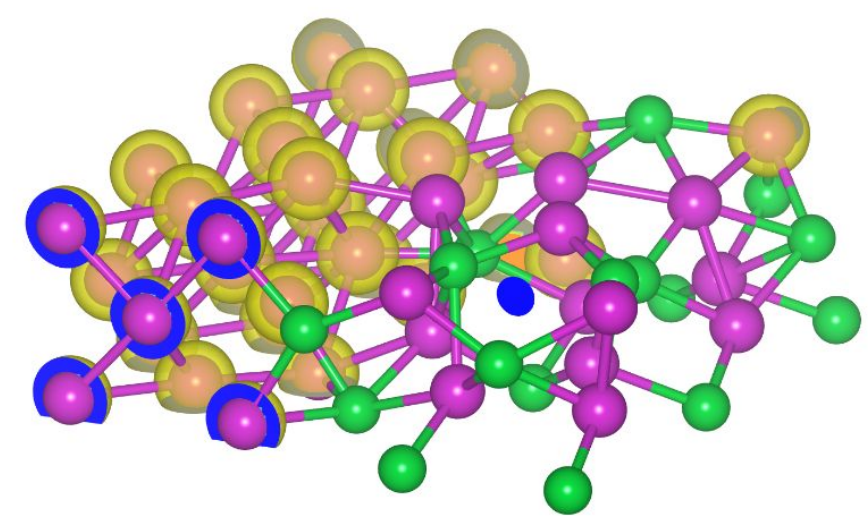

Figure S29. The electron density distribution of the Co, the yellow and cyan regions represent charge accumulation and depletion. The isovalues are $0.005 \mathrm{eV} / \AA 3$. The pink and green balls represent $\mathrm{Co}$ and $\mathrm{P}$ atoms, respectively.

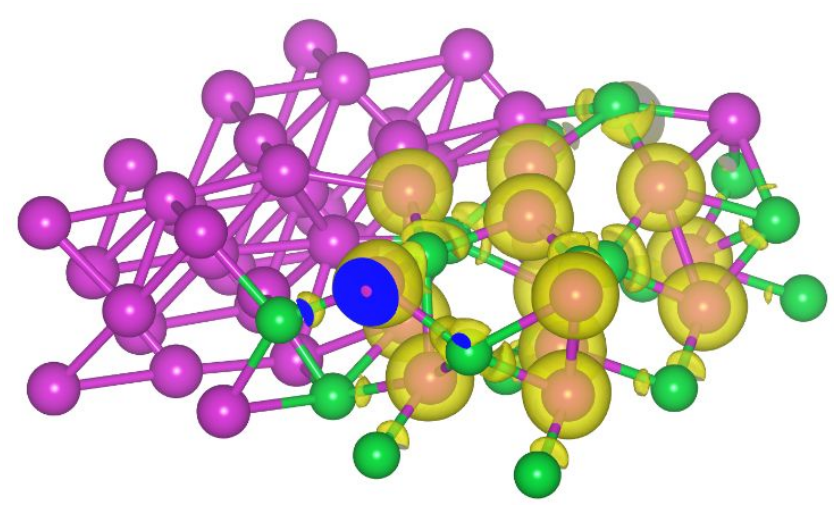

Figure S30. The electron density distribution of the CoP, the yellow and cyan regions represent charge accumulation and depletion. The isovalues are $0.005 \mathrm{eV} / \AA \AA 3$. The pink and green balls represent $\mathrm{Co}$ and $\mathrm{P}$ atoms, respectively. 
Table S1. ICP-MS analysis of Co ions of CoP/Co-n samples.

\begin{tabular}{|c|c|c|c|c|}
\hline & $\mathrm{CoP} / \mathrm{Co}-5$ & $\mathbf{C o P} / \mathbf{C o}-\mathbf{1 0}$ & $\mathrm{CoP} / \mathrm{Co}-20$ & $\mathbf{C o P} / \mathbf{C o}-30$ \\
\hline Co content (wt\%) & 41.50 & 36.73 & 32.51 & 36.93 \\
\hline
\end{tabular}

Table S2. Atomic concentrations at the surface of the Co NPs and CoP/Co-n samples determined by XPS.

\begin{tabular}{|c|c|c|c|c|}
\hline & C (at \%) & Co (at \%) & N (at \%) & P (at \%) \\
\hline Co NPs & 82.18 & 8.99 & 8.84 & - \\
\hline CoP/Co-5 & 73.60 & 8.55 & 8.42 & 9.42 \\
\hline CoP/Co-10 & 76.18 & 5.74 & 6.35 & 11.73 \\
\hline CoP/Co-20 & 74.00 & 6.33 & 6.08 & 13.59 \\
\hline CoP/Co-30 & 76.47 & 5.41 & 6.54 & 11.58 \\
\hline CoP & 49.13 & 14.33 & 1.94 & 34.59 \\
\hline
\end{tabular}

Table S3. Peak assignments from deconvolution of high resolution Co 2p XPS spectra of Co NPs and $\mathrm{CoP} / \mathrm{Co}-\mathrm{n}$ samples.

\begin{tabular}{|c|c|c|c|c|c|}
\hline & \multicolumn{2}{|c|}{ Co $2 \mathbf{p}_{\mathbf{3} / \mathbf{2}}(\mathbf{e V})$} & $\begin{array}{c}\text { Satellite peak } \\
(\mathbf{e V})\end{array}$ & Co $2 \mathbf{p}_{\mathbf{1} / \mathbf{2}}(\mathbf{e V})$ & $\begin{array}{c}\text { Satellite peak } \\
(\mathbf{e V})\end{array}$ \\
\hline Co NPs & \multicolumn{2}{|c|}{780.37} & 785.41 & 795.83 & 803.60 \\
\hline CoP/Co-5 & 778.52 & 781.81 & 786.15 & 797.83 & 803.22 \\
\hline CoP/Co-10 & 778.55 & 782.20 & 786.41 & 798.13 & 803.50 \\
\hline CoP/Co-20 & 778.94 & 782.04 & 785.35 & 798.19 & 803.17 \\
\hline CoP/Co-30 & 778.85 & 782.39 & 786.32 & 798.41 & 803.35 \\
\hline CoP & 779.15 & 782.50 & 786.94 & 798.70 & 803.91 \\
\hline
\end{tabular}

Table S4. Peak assignments from deconvolution of high resolution P 2p XPS spectra of CoP/Co-n samples.

\begin{tabular}{|c|c|c|c|}
\hline & $\left.\mathbf{P ~ 2}_{\mathbf{3} / \mathbf{2}} \mathbf{( e V}\right)$ & $\left.\mathbf{P ~ 2}_{\mathbf{1 / 2}} \mathbf{( e V}\right)$ & $\left.\mathbf{P}_{-}-\mathbf{O}_{\mathbf{x}} \mathbf{( e V}\right)$ \\
\hline CoP/Co-5 & 129.80 & 130.70 & 134.07 \\
\hline CoP/Co-10 & 129.50 & 130.32 & 134.46 \\
\hline CoP/Co-20 & 129.94 & 130.92 & 134.40 \\
\hline CoP/Co-30 & 129.94 & 130.92 & 134.73 \\
\hline CoP & 129.92 & 130.92 & 134.71 \\
\hline
\end{tabular}

Table S5. Statistical results of BET surface area and BJH adsorption average pore diameter of Co NPs and CoP/Co-n samples.

\begin{tabular}{|c|c|c|}
\hline & BET Surface Area $\left(\mathbf{m}^{\mathbf{2}} / \mathbf{g}\right)$ & BJH Adsorption average pore diameter $(\mathbf{n m})$ \\
\hline Co NPs & 76.0635 & 23.9743 \\
\hline CoP/Co-5 & 20.0236 & 41.7175 \\
\hline CoP/Co-10 & 1.1728 & 75.9664 \\
\hline CoP/Co-20 & 1.8142 & 64.2037 \\
\hline CoP/Co-30 & 1.8977 & 36.8849 \\
\hline
\end{tabular}


Table S6. Comparison of the electrocatalytic activities of Co NPs and CoP/Co-n samples for $\mathrm{HzOR}$.

\begin{tabular}{|c|c|c|}
\hline & Potential@10 mA cm-2 $(\mathrm{mV})$ & Potential@100 mA cm cm $^{-2}(\mathrm{mV})$ \\
\hline Co NPs & -24 & 357 \\
\hline $\mathrm{CoP} / \mathrm{Co}-5$ & -44 & 279 \\
\hline CoP/Co-10 & -51 & 238 \\
\hline CoP/Co-20 & -69 & 177 \\
\hline CoP/Co-30 & -46 & 252 \\
\hline CoP & -49 & 202 \\
\hline
\end{tabular}

Table S7. Comparison of the electrocatalytic activities of $\mathrm{CoP} / \mathrm{Co}-20$ with other reported cobalt based and precious metal base materials for $\mathrm{HzOR}$.

\begin{tabular}{|c|c|c|c|c|}
\hline Materials & Electrolyte & $\mathrm{J}(\mathrm{mA} / \mathrm{cm} 2)$ & Potential (mV) & Reference \\
\hline \multirow[t]{2}{*}{$\mathrm{CoP} / \mathrm{Co}-20$} & $1.0 \mathrm{M} \mathrm{KOH}+0.5 \mathrm{M}$ & 10 & -69 & \multirow[t]{2}{*}{ This work } \\
\hline & $\mathrm{N}_{2} \mathrm{H}_{4}$ & 100 & 177 & \\
\hline $\mathrm{CoSe}_{2}$ & $\begin{array}{l}1.0 \mathrm{M} \mathrm{KOH}+0.5 \mathrm{M} \\
\mathrm{N}_{2} \mathrm{H}_{4}\end{array}$ & 10 & -17 & Ref. $4^{5}$ \\
\hline $\mathrm{Co}_{3} \mathrm{Ta} / \mathrm{C}$ & $\begin{array}{l}3.0 \mathrm{M} \mathrm{KOH}+0.5 \mathrm{M} \\
\mathrm{N}_{2} \mathrm{H}_{4}\end{array}$ & 10 & -39 & Ref. $5^{6}$ \\
\hline $\begin{array}{l}\mathrm{PW}-\mathrm{Co}_{3} \mathrm{~N} \\
\mathrm{NWA} / \mathrm{NF}\end{array}$ & $\begin{array}{l}1.0 \mathrm{M} \mathrm{KOH}+0.1 \mathrm{M} \\
\mathrm{N}_{2} \mathrm{H}_{4}\end{array}$ & 10 & -55 & Ref.6 $6^{7}$ \\
\hline $\mathrm{CoS}_{2}$ & $\begin{array}{l}1.0 \mathrm{M} \mathrm{KOH}+0.1 \mathrm{M} \\
\mathrm{N}_{2} \mathrm{H}_{4}\end{array}$ & 100 & 205 & Ref. $2^{3}$ \\
\hline $\mathrm{RuP}_{2}$ & $\begin{array}{l}1.0 \mathrm{M} \mathrm{KOH}+0.3 \mathrm{M} \\
\mathrm{N}_{2} \mathrm{H}_{4}\end{array}$ & 10 & -70 & Ref. $7^{8}$ \\
\hline
\end{tabular}

Table S8. Comparison of the Tafel slope of Co NPs, CoP and CoP/Co-n samples for HzOR.

\begin{tabular}{|c|c|c|c|c|c|c|}
\hline & Co NPs & CoP/Co-5 & CoP/Co-10 & CoP/Co-20 & CoP/Co-30 & CoP \\
\hline $\begin{array}{c}\text { Tafel slope } \\
\text { (mV/dec) }\end{array}$ & 63.33 & 31.67 & 29.24 & 26.52 & 39.36 & 34.87 \\
\hline
\end{tabular}

Table S9. Comparison of the $\mathrm{C}_{\mathrm{dl}}$, ECSA and RF of Co NPs, CoP and CoP/Co-n samples for $\mathrm{HzOR}$.

\begin{tabular}{|c|c|c|c|c|c|c|}
\hline & Co NPs & $\mathrm{CoP} / \mathrm{Co}-5$ & CoP/Co-10 & CoP/Co-20 & CoP/Co-30 & CoP \\
\hline $\begin{array}{c}\mathrm{C}_{\mathrm{dl}} \\
\left(\mathrm{mF} / \mathrm{cm}^{2}\right)\end{array}$ & 14.93 & 2.84 & 6.24 & 3.83 & 2.80 & 5.14 \\
\hline $\begin{array}{c}\text { ECSA } \\
\left(\mathrm{cm}^{2}\right)\end{array}$ & 48.77 & 9.27 & 20.38 & 12.51 & 9.14 & 16.79 \\
\hline RF & 248.83 & 47.33 & 104 & 63.83 & 46.67 & 85.73 \\
\hline
\end{tabular}


Table S10. Comparison of the $\mathrm{R}_{\mathrm{ct}}$ of Co NPs, CoP and CoP/Co-n samples for HzOR.

\begin{tabular}{|c|c|c|c|c|c|c|}
\hline & Co NPs & CoP/Co-5 & CoP/Co-10 & CoP/Co-20 & CoP/Co-30 & CoP \\
\hline $\mathbf{R}_{\text {ct }}(\mathbf{\Omega})$ & 4.66 & 4.23 & 3.27 & 2.71 & 3.17 & 4.07 \\
\hline
\end{tabular}

\section{References}

(1) Yan, N.; Zhao, Z.; Li, Y.; Wang, F.; Zhong, H.; Chen, Q. Synthesis of novel two-phase Co@SiO(2) nanorattles with high catalytic activity. Inorg Chem 2014, 53 (17), 9073-9, DOI: 10.1021/ic501092k.

(2) Wang, C.; Liu, S.; Wang, D.; Chen, Q. Interface engineering of Ru-Co3O4 nanocomposites for enhancing CO oxidation. Journal of Materials Chemistry A 2018, 6 (23), 11037-11043, DOI: 10.1039/c8ta00994e.

(3) Liu, X.; He, J.; Zhao, S.; Liu, Y.; Zhao, Z.; Luo, J.; Hu, G.; Sun, X.; Ding, Y. Self-powered H2 production with bifunctional hydrazine as sole consumable. Nat Commun 2018, 9 (1), 4365, DOI: 10.1038/s41467018-06815-9.

(4) Hou, C.-C.; Li, Q.; Wang, C.-J.; Peng, C.-Y.; Chen, Q.-Q.; Ye, H.-F.; Fu, W.-F.; Che, C.-M.; López, N.; Chen, Y. Ternary $\mathrm{Ni}-\mathrm{Co}-\mathrm{P}$ nanoparticles as noble-metal-free catalysts to boost the hydrolytic dehydrogenation of ammonia-borane. Energy \& Environmental Science 2017, 10 (8), 1770-1776, DOI: 10.1039/c7ee01553d.

(5) Zhang, J. Y.; Wang, H.; Tian, Y.; Yan, Y.; Xue, Q.; He, T.; Liu, H.; Wang, C.; Chen, Y.; Xia, B. Y. Anodic Hydrazine Oxidation Assists Energy-Efficient Hydrogen Evolution over a Bifunctional Cobalt Perselenide Nanosheet Electrode. Angew Chem Int Ed Engl 2018, 57 (26), 7649-7653, DOI: 10.1002/anie.201803543. (6) Feng, G.; An, L.; Li, B.; Zuo, Y.; Song, J.; Ning, F.; Jiang, N.; Cheng, X.; Zhang, Y.; Xia, D. Atomically ordered non-precious CO3Ta intermetallic nanoparticles as high-performance catalysts for hydrazine electrooxidation. Nat Commun 2019, 10 (1), 4514, DOI: 10.1038/s41467-019-12509-7.

(7) Liu, Y.; Zhang, J.; Li, Y.; Qian, Q.; Li, Z.; Zhu, Y.; Zhang, G. Manipulating dehydrogenation kinetics through dual-doping Co3N electrode enables highly efficient hydrazine oxidation assisting self-powered H2 production. Nat Commun 2020, 11 (1), 1853, DOI: 10.1038/s41467-020-15563-8.

(8) Yapeng Li, J. Z., Yi Liu, Qizhu Qian, Ziyun Li, Yin Zhu, Genqiang Zhang. Partially exposed RuP2 surface in hybrid structure endows its bifunctionality for hydrazine oxidation and hydrogen evolution catalysis. Sci. Adv. 2020, 6. 